\title{
Örgüt Kültürü ile Örgütsel Sessizlik Arasındaki İlişkinin İncelenmesi ${ }^{1}$
}

Örgüt Kültürü ile Örgütsel Sessizlik Arasındaki İlişkinin İncelenmesi

Öz

Bu araştırmanın amacı, örgüt kültürü ile örgütsel sessizlik arasındaki ilişkinin açıklanmasıdır. Araştırmanın evreni Burdur il Merkezindeki kamu kurumlarında görev yapmakta olan çalışanlardan oluşmaktadır. Veri toplama yöntemi olarak anket tekniği kullanılmış olup, yapılan uygulama sonucunda 831 anket değerlendirmeye alınarak analiz edilmiştir. Araştırma modelinde yer alan örgüt kültürü ile örgütsel sessizlik boyutları arasındaki ilişkileri belirlemek amacıyla korelasyon analizinden faydalanılmıştır. Buna göre klan ve adhokrasi kültürleri ile üst yönetime güvensizlikten kaynaklanan sessizlik arasında negatif yönde ve çok düşük düzeyde, hiyerarşi kültürü ile üst yönetime güvensizlikten kaynaklanan sessizlik arasında pozitif yönde ve çok düşük düzeyde, pazar kültürü ile prososyal eğilime dayalı sessizlik arasında pozitif yönde ve çok düşük düzeyde bir ilişki olduğu sonucuna ulaşılmıştır.

Anahtar Kelimeler: Örgüt Kültürü, Rekabetçi Değerler Modeli, Örgütsel Sessizlik
The Analysis of the Relationship between Organizational Culture and Organizational Silence

\section{Abstract}

The purpose of this research is to explain the relationship between organizational culture and organizational silence. The universe of the research consists of the employees working in the public institutions in Burdur city center. Survey method is used for data collection and 831 questionnaires are evaluated and obtained data are analyzed. Correlation analysis is used to determine the relationship between organizational culture and organizational silence dimensions included in the research model. As result of research, it is found that there is negative and very low level of relationship between the clan and adhocracy cultures and silence from the lack of confidence in senior management, positive and very low level relationship between the hierarchy culture and silence from lack of confidence in senior management, positive and a very low level of relationship between market culture and tendency towards prosocial behavior based silence.

Keywords: Organizational Culture, Competing Values Framework, Organizational Silence

\section{Giriş}

Teknolojinin gelişmesi ile birçok sorunun üstesinden gelinebileceği düşünülse de örgütlerin değişen koşullara uyum sağlayarak varlıklarını devam ettirebilmeleri için ihtiyaç duyulan en önemli faktör insandır ve örgütü çalışanlarından bağımsız olarak düşünmek mümkün değildir. Örgüt ile çalışanlar arasındaki uyumu sağlayacak davranış biçimlerinin geliştirilebilmesi için, çaıışanların her koşulda kendilerini ifade edebilecekleri ve her koşulda söz sahibi olabilecekleri bir örgüt kültürünün oluşturulması, olumsuz durumlar karşısında bile çalışanların fikir ve düşüncelerini korkusuzca ifade edebilmelerine imkân tanınması gerekmektedir. Örgütsel sessizliği destekleyen bir örgüt kültüründe, örgüt üyeleri tarafından paylaşılan sessizliğin örgüt kültürüne

\footnotetext{
${ }^{1}$ Bu çalışma Süleyman Demirel Üniversitesi Sosyal Bilimler Enstitüsü Iş̧letme Anabilim Dalı’nda Prof. Dr. Ramazan Erdem danışmanlığında Gamze Macit tarafından “Örgüt Kültürü Ile Örgütsel Sessizlik Arasındaki ilişkilerin İncelenmesi” ismiyle tamamlanarak 20.06.2017 tarihinde savunulan doktora tezinden türetilmiştir.

2Dr., Burdur Çevre ve Şehircilik II Müdürlüğü, gamzemacit@hotmail.com, Yazar ORCID bilgisi: http://orcid.org/00000001-6003-8738

${ }^{3}$ Prof. Dr., Süleyman Demirel Üniversitesi, iỉBF, Sağlık Yönetimi Bölümü. ramazanerdem@sdu.edu.tr, Yazar ORCID bilgisi: http://orcid.org/0000-0002-5986-8280
} 
yerleşmesi kaçınılmaz bir durumdur. Örgütlerin bilgilerini ve düşüncelerini paylaşmaktan ve risk almaktan korkmayan çalışanlara ihtiyacı vardır.

Çalışanların konuşmayı ya da sessizliği tercih etmesi örgüt kültürünün bir sonucu olarak değerlendirilebilir. Çalışanların örgütsel davranışları, hâkim örgüt kültürünün bir sonucu olarak ele alındığında, sessizlik davranışının da kültürel bağlamda değişiklikler göstermesi beklenmektedir (Aktaş ve Şimşek, 2014: 25).

Örgütlerde yaygın olarak görülen, endişe verici bir durum olan ve bir "tepki" göstergesi olarak kabul edilen örgütsel sessizlik kavramı son yıllarda önem kazanmaya başlamıştır. Örgütsel sessizlik, örgütler kadar çalışanları da olumsuz etkileyebilen bir süreçtir ve çalışanların açıkça konuşmayı ya da sessizliği tercih etmeleri örgüt kültürü ile yakından ilgilidir. Örgüt kültürü, örgütsel sessizliğinin başlıca nedenleri arasındadır ve çalışanların sessizlik tercihlerinin örgütlerdeki kültürel değerler açısından ele alınması önemlidir.

Literatürde örgüt kültürü ile örgütsel sessizlik konularını ele alan çalışmalar bulunmaktadır. Örneğin; Premeaux ve Bedian (2003) sessizlik ile kendine güven, kontrol odağı ve kendini izleme davranışının iliş̧kisini, Aşkun vd. (2010) sessizlik ve güç mesafesi arasındaki ilişkiyi, Erenler (2010) tepe yönetimin açıklığının, algılanan örgütsel desteğin, içsel kontrol odağının, duyusal ve zorunlu bağlılığın çalışan sessizlik davranışı üzerinde etkili olup olmadığını, Özen Kutanis ve Karakiraz (2012) ve Karakiraz (2012) işgören sessizliği ile bazı kültürel faktörler (kontrol odağı, bireycilik ve toplulukçuluk) arasındaki ilişkiyi, Tiktaş (2012) örgütsel kültür, örgütsel özdeşleşme ve örgütsel sessizlik kavramları arasındaki ilişkiyi, Ruçlar (2013) öğretim elemanlarının demografik özellikleri ile örgütsel sessizlik ve örgüt kültürü (güç kültürü, rol kültürü, destek kültürü ve başarı kültürü) algıları arasındaki ilişkiyi, Aktaş ve Şimşek (2014) örgütsel sessizlik ile algılanan bireysel performans, örgüt kültürü ve demografik değişkenler arasındaki etkileşimi, Çaloğlu (2014) örgütsel sessizlik ile Hofstede'nin kültür modelinin alt boyutları olan bireycilik ve toplulukçuluk arasındaki ilişkiyi, Radmard ve Ardakani (2014) örgütsel bağıılığın aracılığı ile örgüt kültürünün örgütsel sessizlik üzerindeki etkisini araştırmışlardır (Çavuşoğlu ve Köse, 2016: 119). Acaray ve Şevik (2016) tarafından yapılan araştırmada, güç mesafesi ve toplulukçuluk ile örgütsel sessizlik boyutları arasındaki ilişki incelenmiştir. Acaray vd. (2015) ile Çavuşoğlu ve Köse (2016) tarafından yapılan araştırmalarda ise rekabetçi değerler modelindeki dört kültür tipinin örgütsel sessizlik üzerindeki etkileri incelenmiştir. Literatürde örgütsel sessizlik ile ilgili birçok araştırma yapılmış olmasına rağmen, rekabetçi değerler modelindeki örgüt tipleri ile örgütsel sessizlik arasındaki ilişkileri belirlemeye yönelik araştırmaların sayısı oldukça azdır. Literatürdeki bu boşluktan hareketle, bu araştırmada, hangi örgüt kültürü tipinde hangi örgütsel sessizlik türünün görüldüğü sorusundan yola çıkılarak, farklı özellikteki yapıları ayırt etmeye ve zıt özelliklerin değerlendirilmesine imkân tanıyan ve en çok kullanılan örgüt kültürü modellerinden olan rekabetçi değerler modelindeki örgüt kültürü tipleri ile örgütsel sessizlik arasındaki ilişkinin örgütsel düzeyde belirlenmesi amaçlanmıştır.

\section{Kavramsal Çerçeve}

\section{1. Örgüt Kültürü}

Literatürde çeşitli şekillerde örgüt kültürü tanımları yapıldığı görülmektedir. Örgüt kültürü örgütsel davranış biçimleri, semboller ve sembolik hareketler vasıtasıyla somutlaşarak kesinlik kazanan, örgüt üyelerinin davranış, tutum ve kararlarını biçimlendiren, simgeler yardımı ile öğrenilen ve nesilden nesile aktarılan ortak değerler, inançlar ve normlar bütünüdür (Ataman Unutkan, 1995: 40, Dinçer, 1998: 348). 
Örgüt kültürü, belirli bir grubun, dış adaptasyon ve içsel bütünleşme sorunları ile başa çıkmak amacıyla geliştirdikleri varsayımlardır (Schein, 1983: 1-2). Deshpande ve Webster (1989)'a göre ise örgüt kültürü, kişinin örgütsel işleyişi anlamasına yardımcı olan ve örgüt içindeki davranışları ile ilgili normlar sağlayan ortak değer, yargılar ve inançlar düzenidir (Eren, 2000: 119).

Örgüt kültürü, örgütlerin hayatta kalmalarında önemli bir yere sahiptir. Örgüt kültürü, birçok disiplinden kavramlar, modeller ve yöntemler alıp kullanan, birden fazla bilim dalıyla ilgili olan ve farklı disiplinlerin kesişiminden oluşan bir araştırma alanıdır (Can vd., 2006: 427).

\section{2. Örgüt Kültürü Modelleri}

Bazı yazarlar mükemmellik yaklaşımı ile tek ve en iyi kültür arayışında iken (Peters ve Waterman, 1982) bazı yazarlar ise farklı kültür türlerini açıklayan kültür tipolojileri geliştirmişlerdir. Her örgütün farklı bir kültür yapısı vardır ancak benzer özellikler taşıyan örgüt kültürlerini bir araya toplayarak belirli modellerin oluşturulması oldukça faydalı ve gereklidir (Ataman Unutkan, 1995: 56). Kültürler arasındaki farklılıkların nedenlerine ilişkin çok sayıda araştırma bulunmaktadır. Kültür kavramını "ortak zihinsel programlama” olarak tanımlayan Hofstede (1980), araştırmasında, farklı kültürlere ait insanların nasıl ve nelerden etkilendiğini anlamaya yardımcı olabilecek dört boyut belirlemiştir. Bunlar güç mesafesi, belirsizlikten kaçınma, bireysellik ve toplulukçuluk, erkeklik ve dişilik kültür boyutlarıdır.

Örgüt kültüründe sosyal değerlerin katkıları üzerinde duran Parsons'un örgüt kültürü modelinde; uyum, amaca ulaşma, bütünleşme ve yasallık olmak üzere dört işlev bulunmaktadır ve Parsons her sosyal sistemde bu işlevlerin bulunması gerektiğini savunmaktadır. Parsons'un örgüt kültürü modelinde kültürel değerler önemli araçlardır ve bu değerler aracılığı ile örgütler hızlı değişimlere ve gelişmelere ayak uydurabilir. Örgütlerde kültür oluşumuna katkıda bulunan belirleyici değerleri teknik, ekonomik, sosyal, psikolojik, politik, estetik, ahlaki ve dini değerler şekilde sınıflandırmak mümkündür (Akt. Eren, 2000: 126-128; Özkalp ve Kırel, 2003: 150-151).

Deal ve Kennedy (1982)'nin örgüt kültürü modelinde daha çok örgüt dışı çevresel faktörlerin kültür üzerindeki etkisi vurgulanmıştır. Bu modelde, çevre ile örgüt kültürü arasındaki ilişkiler iki boyutlu değişken üzerinde dört farklı kültüe tipi olarak açıklanmaktadır. Örgütün faaliyetleri ile ilişkili olarak alınan risk derecesi ve başarılı kararlar ya da stratejilerde geribildirime göre şekillenen kültür tipleri sert adam/maço kültürü, çok çalış/sert oyna kültürü, şirketin üzerine iddiaya gir kültürü ve süreç kültürüdür (Eren, 2000: 136; Deal ve Kennedy, 1982: 107-112).

Japon ve Amerikan yönetim tarzları arasındaki büyük farklılıkları vurgulayan ve karşılaştırmalı olarak inceleyen William Ouchi (1981)'ye göre insanlar, aynı koşullarda benzer tepkiler göstermektedir ancak her kültür, kendi üyeleri için bir başka kültürden çok farklı koşullar oluşturmaktadır (Eren, 2000: 142). Ouchi (1981), "Z" Kültürü Modeli ile örgüt kültürünü "Japon Örgütlerindeki Görünüm”, “Amerikan Z Tipi Örgütlerindeki Görünüm” ve "Tipik Amerikan Örgütlerindeki Görünüm" olmak üzere üç ayrı grupta toplayarak incelemiştir ve yedi temel ölçütten yola çıkarak bu üç kültür tipini kıyaslamıştır (Moorhead and Griffin,1989; Akt. Özkalp ve Kırel, 2003: 169).

Literatürde yaygın olarak kullanılan diğer bir örgüt kültürü modeli ise, örgütün kültürel profilini daha net ortaya koyması nedeniyle araştırma kapsamında örgüt kültürü ile örgütsel sessizlik arasındaki ilişkiyi belirlemede kullanılan Cameron ve Quinn'in (1983) rekabetçi değerler modelidir ve bu modele ait bilgilere aşağıda yer verilmiştir. 


\subsubsection{Rekabetçi Değerler Modeli}

Cameron ve Quinn'in rekabetçi değerler modeli, bir değerlendirme ve ölçüm aracını da içermesi nedeniyle, kültürle ilgili sınıflandırmalar içerisinde yaygın bir şekilde kullanılmaktadır (Acaray vd., 2015: 142). Hem farklı özellikteki yapıları ayırt etmeye hem de zıt özelliklerin değerlendirilmesine imkân tanıyan rekabetçi değerler modeli, bir örgütün mevcut veya sahip olmak istediği kültürel profilini ortaya koyan, böylece kültürel değişimi amaçlayan yöneticilere yol gösterici özelliği olan bir örgüt kültürü modelidir (Hooijberg ve Petrock, 1993). Bu araştırmada, örgüt kültürü ile örgütsel sessizlik arasındaki ilişkiyi belirlemek için, farklı özellikteki yapıları ayıt etme imkânı vermesi ve zıt özelliklerin varlığının değerlendirilmesine olanak tanıması nedeniyle rekabetçi değerler modelindeki örgüt kültürü tiplerinden faydalanılmıştır.

Cameron ve Quinn (1983), rekabetçi değerler adını verdikleri örgüt kültürü modelinde, örgüt kültürü ile örgütsel başarı arasındaki ilişkileri inceleyerek, örgüt kültürü ve bu kültürün örgütsel başarı veya etkinliğe olan etkilerini araştırmışlardır. Cameron ve Quinn (1983), geliştirdikleri dört basamaklı örgütsel hayat döngüsü modelinde her basamaktaki örgütleri belirgin birkaç özellikleri ile ayrı ayrı tanımlamışlardır (Akt. Eren, 2000: 131, Erdem vd., 2010: 77). Rekabetçi değerler modeli, dört kadranı tanımlayan iki eksene sahiptir. Illk eksen istikrar, düzen ve kontrolü vurgulayan ölçütlerden esneklik, takdir yetkisi ve dinamizm etkililik ölçütlerini ayırt etmektedir. İkinci eksen, iç yönelim, bütünleşme ve birliği vurgulayan etkinlik ölçütlerini dış yönelim, farklılaşma ve rekabeti vurgulayan ölçütlerden ayırmaktadır. Üst sol kadran iç odaklanmaya ve organik süreçlere, sağ üst kadran dış odaklanmaya ve organik süreçlere, sol alt kadran iç odaklanmaya ve mekanik süreçlere, sağ alt kadran ise dış odaklanmaya ve mekanik süreçlere odaklanmaktadır. Her kadranda rakip veya zıt örgüt kültürü tiplerinin yer alması nedeniyle bu modele "Rekabetçi Değerler Modeli" adı verilmiştir. Her kadranın temel varsayımları, yönelimleri ve değerleri vardır ve bu nedenle her kadran kültürel bir tip olarak tanımlanmıştır (Cameron ve Quinn, 2011: 38-41). Rekabetçi değerler modelini tanımlayan iki eksenin birbirleriyle olan ilişkileri Şekil 1'de yer almaktadır.

Şekil 1. Rekabetçi Değerler Modelinin Boyutları

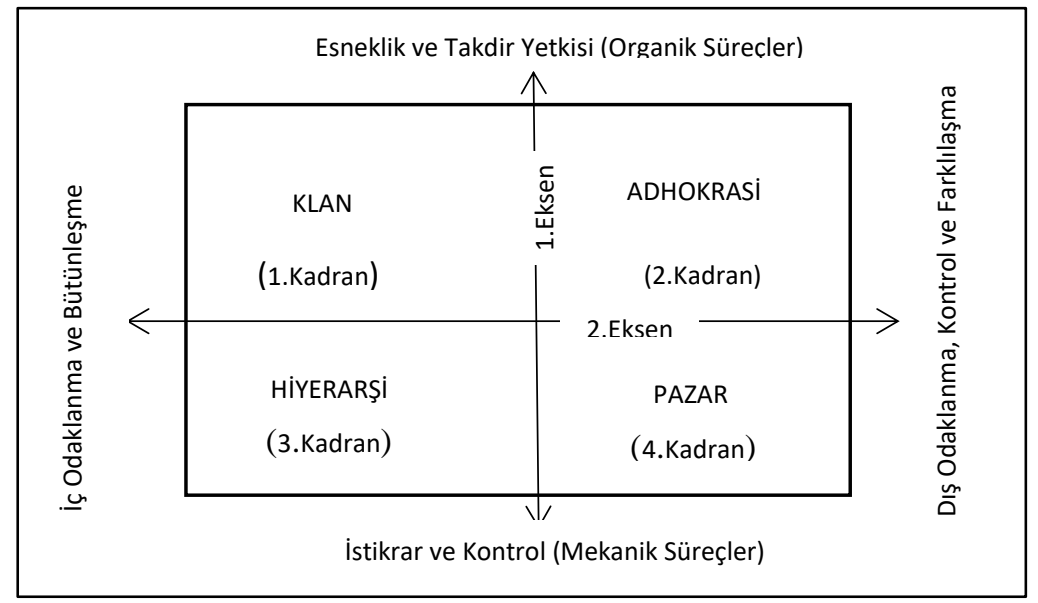

Kaynak: (Cameron ve Quinn, 2011: 39) 
Cameron ve Quinn'in (2011) örgüt kültürü modelinde, iki boyuttan ortaya çıkan kültür tipleri klan, adhokrasi, hiyerarşi ve pazar kültürü olmak üzere dört boyuta ayrılmıştır.

\subsubsection{Klan Kültürü (İş Birliğine Dayalı Kültür)}

Aile tipi bir örgüte benzerliği nedeniyle klan olarak adlandırılan bu örgüt kültürü tipinde, hiyerarşilerin kuralları ve prosedürleri ya da pazarların rekabetçi kâr merkezleri yerine, takım çalışması, çalışan katılım programları ve örgütsel bağlıık önem kazanır (Cameron ve Quinn, 2011: 46-48). Klan kültüründe örgüt, çevresel değişimlere karşı hızlı tepki verebilme yeteneği sağlayan informal mekanizmalar ile kontrol edilir ve formalizasyon oldukça düşüktür. Çalışanların davranışlarına yön veren örgütsel gelenekler vardır ve bu nedenle klan kültüründe örgütsel uyumu bozan kişiler dışlanmakta ve cezalandırılmaktadır (Erdem, 2007b: 111).

\subsubsection{Adhokrasi Kültürü (Girişimci Kültür)}

Yirmi birinci yüzyılın örgütsel dünyasını giderek daha fazla simgeleyen, dışsallığa, rekabet ve farklılaşmaya odaklanan, esnek yapı ve süreçlere önem veren, hiperaktif ve her geçen gün hızlanan koşullara en hızlı tepkiyi veren örgüt kültürü tipi adhokrasi kültürüdür. Hiyerarşi ya da pazar kültürlerinin aksine, adhokratik örgütlerde bir otorite ya da güç ilişkisi bulunmamaktadır. Sorunun ne olduğuna bağlı olarak, güç bireyden bireye veya ekipten ekibe değişmektedir. Bireysellik, risk alma ve geleceği ön plana çıkarmanın önemi yüksektir (Cameron ve Quinn, 2011: 49-51).

\subsubsection{Hiyerarşi (Kontrol) Kültürü}

Hiyerarşi kültürünün egemen olduğu örgütlerde, çalışanlar kendilerini güven içinde hissedebilmek için belirsiz durumlardan kaçınırlar ve değişim politikalarına ihtiyatla yaklaşırlar (Erdem, 2007b: 111). Düzen ve kuralların önemli olduğu hiyerarşi kültüründe bulunan katı hiyerarşik yapı insiyatif kullanma ve karar verme alışkanlığı kazanmayı önlemektedir. Yukarıdan aşağıya emir verme, aşağıdan yukarıya ise sorumluluk aktarma geleneği yerleşik bir tutumdur. Hiyerarşik kademelerin fazlalı̆̆ı astlar ile üstler arasındaki iletişimsizliği arttırarak, astların şikâyetlerinin ve isteklerinin üst kademelere iletilirken hiyerarşik kademelerde kaybolmasına ya da değişikliğe uğramasına neden olmaktadır. Yukarıdan aşağıya doğru akışta bilgi kademelerden geçtikçe abartılmakta, aşağıdan yukarıya doğru iletişimde ise bilgi değerini kaybetmekte, anlam kayması, öneminin azalması, vurgunun yer değiştirmesi gibi durumlar ortaya çıkabilmektedir (Aytaç, 2007: 166).

\subsubsection{Pazar (Rekabet) Kültürü}

Bir pazarın kendisi olarak işlev gören örgüt tipi olan pazar kültürü, pazarlama işleviyle veya piyasadaki tüketicilerle eş anlamlı değildir (Cameron ve Quinn, 2011: 43-46). Pazar kültüründe somut başarılar elde etmek, kazanma duygusu ve rekabetçilik ön plana çıkarken, diğer taraftan pazar kültürü biçimselleşme ve durağanlık özelliklerine de sahiptir (Erdem, 2007a: 73). Pazar kültürü, sonuç odaklıdır ve örgütü bir arada tutan kazanma amacıdır. Uzun vadeli kaygı, rekabetçi eylemlerde amaç ve hedeflere ulaşmaktır. Pazar payını arttırmak, rekabette öne geçmek ve pazar liderliğini sağlamak önemlidir (Cameron ve Quinn, 2011: 46).

\section{3. Örgütsel Sessizlik}

Örgütsel sessizlik konusunda önemli çalışmaları bulunan Morrison ve Milliken (2000)'e göre örgütsel sessizlik, çalışanların örgüt ile ilgili konu veya problemlerle ilgili düşünce, görüş ve fikirlerini açıkça ifade etmeyerek, bunları kendilerine saklamasıdır (706-707). Pinder ve Harlos'a 
(2001:334) göre ise, adaletsizliğe karşı bir tepki olarak ortaya çıkan örgütsel sessizlik, örgüt üyelerinin örgütsel koşullar ile ilgili duygusal, davranışsal ve bilişsel değerlendirmelerini, içinde bulunulan durumu etkileyebilecek veya düzeltebilecek kişilere bilerek ve isteyerek söylememesidir.

Örgütsel sessizlik, çalışanların işleri ile ilgili teknik ve davranışsal sorunlar hakkındaki bilgi, görüş ve düşüncelerini bilinçli olarak üstlerine iletmeyerek sessiz kalmayı tercih etmeleridir (Çakıcı, 2010: 10). Kavram ilk başta iletişime kapalı olma durumunu çağrıştırsa da, aslında etkili bir iletişim tarzıdır. Çünkü çalışanlar sessiz kalarak birçok konuda çalışma arkadaşlarına, yöneticilere, örgüte çeşitli mesajlar iletmektedirler (Özgen ve Sürgevil, 2009: 303).

Çalışanların büyük çoğunluğu, diğer çalışanların önerilerine rıza gösteren bir tutum sergileyerek örgütün fikirlerine uyum gösterirler. Dolayısıyla tüm bu durumlar çerçevesinde çalışanların gösterdikleri bu tip davranışlar, örgütsel sessizlik kavramı ile yerini bulmaktadır (Taşkıran, 2011: 69).

Örgütsel sessizlik konusuna çok az ilgi gösterilmesinin iki sebebi vardır. Bunlardan ilki, sessizliğin "konuşmanın noksanlığı" olarak görülmesi ve dikkat çekmemesidir. İkincisi ise, daha açık ve görünür bir davranışa göre, bu davranış eksikliğinin araştırılmasının daha zor olmasıdır (Van Dyne vd., 2003:1363-1364). Örgütsel sessizliğin kendi içinde çelişkili, sübjektif ve karmaşık bir yapısı vardır fakat bu karmaşıklık ve irrasyonelliğin içinde kendine has bir ahengi ve sınırlı bir rasyonelliği bulunmaktadır (Öztürk ve Cevher, 2016: 72).

\section{4. Örgütsel Sessizlik Türleri}

Çalışanların kasıtlı olarak görüş, bilgi ve düşüncelerini kendilerine saklamaları sonucunda ortaya çıkan örgütsel sessizlik, kimi zaman diğer kişilerin görüşlerine uyum sağlamak, kimi zaman da kendini ya da başkalarını koruma düşüncesi ile sessiz kalmak gibi farklı şekillerde ortaya çıkabilmektedir (Taşkıran, 2011: 76). Sessizlik, kişinin aktif olarak iletişim kurmaması olarak düşünülse de sessizlik yalnızca sesten yoksun olmak değildir, çalışanların fikirleri, bilgileri ve görüşleri olmasına rağmen, bu bilgileri, görüşleri ve fikirleri bilinçli olarak ifade etmemeyi seçme durumudur. Farklı sessizlik biçimleri, farklı güdüler tarafından yönlendirilmektedir (Van Dyne vd., 2003: 1366).

Van Dyne vd.'nin (2003) çalışmasında örgütsel sessizlik türleri; kabullenici, savunma (korunma) amaçlı ve koruma amaçlı (örgüt yararına/ prososyal) sessizlik olarak üç başlık altında toplanmıştır. Alparslan vd. (2015) tarafından yapılan araştırmada ise; üst yönetime güvensizlikten kaynaklanan sessizlik, üst yönetimin tepkisinden kaynaklanan sessizlik, ilişkileri bozmamaya dayalı sessizlik, prososyal eğilime dayalı sessizlik, kabullenici ve uysal eğilimden kaynaklanan sessizlik olarak sınıflandırılmıştır. Daha detaylı ve toplumumuza daha uygun olması nedeniyle, bu araştırma kapsamında Alparslan vd. (2015) tarafından yapılan sınıflandırmadan faydalanılmıştır.

\subsubsection{Kabullenici Sessizlik}

Kabullenici sessizlik, çalışanların mevcut duruma razı olup, işsiz kalmama veya terfi edebilmek gibi amaçlar doğrultusunda, görüş, bilgi ve düşüncelerini dile getirmekten kaçınarak pasif bir davranış sergilemeleridir. Kabullenici sessizlikte uysallık ve itaat ön plandadır (Van Dyne vd., 2003: 1366; Öztürk ve Cevher, 2016: 74).

Kabullenici sessizlik kavramının bir parçası olan çalışan itaati, örgütün mevcut şartlarını ve içinde bulunulan durumu sorgulamaksızın kabul etmeyi ve diğer seçeneklerin sınırlılığını ifade 
etmektedir. İtaatkâr ve uysal çalışanlar içinde bulundukları durumları normal olarak kabul ederler ve koşulları olduğu gibi kabul etmek onlara güven verdiği için, mevcut koşulları değiştirmeye çalışmazlar (Pinder ve Harlos, 2001: 349). Kabullenici sessizlikte, bilgi sahibi olmasına rağmen bireylerin iletişim kurmaktan kaçınma davranışı ön plana çıkmaktadır (Özgen ve Süregevil, 2009: 311).

\subsubsection{1. Üst Yönetime Güvensizlikten Kaynaklanan Sessizlik}

Örgütsel sessizliğin temelinde yatan önemli faktörlerden biri, yöneticilerin çoğu zaman çalışanlar ve yönetimin doğası hakkındaki örtük inançlarıdır. Bu inançlardan ilki, çalışanların kendi çıkarlarını düşünen, tembel ve güvenilmez kişiler olduklarıdır. Diğer bir inanç ise, örgütün yararı için en iyi olanı yöneticilerin bileceği inancıdır. Bu inanç yöneticilerin çalışanları "ekonomik insan" olarak düşünmelerinden kaynaklanmaktadır. Çalışanlar bencil ve çalışmaktan kaçınıyorlarsa, muhtemelen örgüt için neyin en iyi olduğunu bilemeyeceklerdir. Son inanç ise, örgüt içinde birlik, anlaşma ve uzlaşmanın olmasının, örgütün sağlıklı olduğunun bir göstergesi olduğu, aksine örgüt içerisindeki uyuşmazlığın ve muhalefetin ise tehlikeli ve kaçınılması gereken bir durum olduğu yönündeki inançtır (Morrison ve Milliken, 2000: 708-710; Durak, 2012: 68). Yöneticilerin inanç ve varsayımları, hem onların davranışlarını ve tercihlerini hem de çalışanları etkiler. Örneğin yöneticiler, çalışanların iş yapmaktan kaçındıklarını varsayarak kontrol mekanizmaları kurarlar. Yönetimin kendilerine güvenmediğini fark eden çalışanlar ise yönetime karşı tavır alarak, sistemlerde boşluklar bulmaya çalışır. Çalışanların bu tepkisi de yöneticilerin ilk inançlarını güçlendirerek bilgi akışını zorlaştıran örgüt yapısı inşa etmesine neden olur (Morrison ve Milliken, 2000: 712-713). Yöneticilerin, çalışanları bencil ve güvenilmez bulmaları, yöneticiler ile çalışanlar arasında güven eksikliğine neden olabilmektedir. Konuşmaları durumunda, üst yönetimin gözüne batmak ve sorun çıkaran biri olarak algılanmak istemeyen, üst yönetimin hakkaniyetine güvenmeyen, konuşmasının bir yarar sağlamayacağını düşünen ve konuşması durumunda üst yönetimin arkasında durmayacağını ve sessiz çalışanı sevdiğini bilen çalışanlar örgütsel sessizliği tercih edebilecektir.

\subsubsection{Kabullenici ve Uysal Eğilimden Kaynaklanan Sessizlik}

Örgüt ortamlarında sessizliği ve sesi anlamada esas teşkil eden temel süreç "yayılma" fikridir. Başka bir deyişle, bir konuda sessizlik olarak başlayan şey, bir dizi konunun sessizliği için yayılabilir ve bir konu hakkındaki sessizlik, diğer konularda da sessizliğin artmasına neden olur. Özellikle kişisel önemi olan bir konudaki sessizlik yayılabilir, çünkü bir kişinin örgütteki diğer insanlarla olan bağlarının gücünü etkiler, diğerlerinden bilinçli olarak bilgi kesintisi ile bağlar zayıflar, bu zayıflamış bağlar, güven düzeyinde bir bozulma ve diğer konularda konuşma ihtimalinin azalmasına neden olur (Milliken ve Morrison, 2003: 1564). Koşulları olduğu gibi kabul etme eğilimde olan ve uysal bir kişiliğe sahip çalışanlar; üst yönetime duydukları saygıdan, üst yönetim ile aralarını bozmamak için, uysal ve sessiz bir yapıları olması, azınlıkta olduklarını düşünmeleri, haklıyken haksız duruma düşmekten korktukları için ya da yasal haklarının yetersiz olması gibi nedenlerle sessiz kalabilmektedirler.

\subsubsection{Savunma (Korunma) Amaçlı Sessizlik}

Savunma amaçlı sessizlik, kendini dış tehlikelerden korumak amacıyla, görüş, bilgi ve düşüncelerini güvence hissi ile kasıtlı olarak kendine saklanmasıdır. Kabullenici sessizliğin aksine, kendini savunma güdüsü ile ortaya çıkan savunma amaçlı sessizlik; endişe ve korku temeline dayanan, kendini dış tehditlerden korumak için tasarlanmış kasıtlı ve proaktif bir davranıştır. Alter- 
natiflerin farkında olan ve korku unsuru ile bu davranışı bilinçli olarak gösteren çalışanlar, sessizliği belli bir zaman diliminde en iyi kişisel strateji olarak düşünmektedir (Van Dyne vd., 2003: 1367). Bilinçli bir risk değerlendirmesine dayandığı ve dışsal tehditlerden kendini koruma niyeti taşıdığı için daha proaktiftir (Çakıcı, 2010: 33). Çalışanlar korkuya dayalı olarak, sorunlar hakkındaki bilgileri saklı tutmayı ya da kendini korumak için gerçekleri görmezden gelmeyi ve kendini korumak için kişisel hataları gizlemeyi tercih edebilirler. Farklı görüş ve fikirlerini yöneticilere iletmeleri durumunda faydadan çok zarar görebileceğini düşünmeleri nedeniyle güvenlik ihtiyacı ön plana çıkmaktadır (Van Dyne vd., 2003: 1367).

\subsubsection{1. Üst Yönetimin Tepkisinden Kaynaklanan Sessizlik}

Narsist kişilik özellikleri sergileyen yöneticilerde sık sık karşılaşılan bir durum olarak, yöneticilerin çalışanlardan gelecek fikirlere değer vermeme ve dikkate almama davranışları sonucunda çalışanlar sessizliği tercih edebilecektir (Öztürk ve Cevher, 2016: 73). Astlardan gelen bilgilere ve görüşlere kapalı, açıkça konuşmayı desteklemeyen ve sorun bildirenlere olumsuz tepkiler veren bir yönetim anlayışı sergileyen, açıkça konuşanları ödüllendirmeyerek gizli veya açık şekilde cezalandıran üst yönetim; örgütsel sessizliği destekleyen bir örgütsel ortam oluşmasına neden olabilirler. Sıkı kontrol mekanizmaları, merkezileşme, dikey hiyerarşik yapı, yukarı doğru iletişim mekanizmalarının eksikliği gibi uygulamalar, çalışanlar arasında, sorunlar hakkında konuşmanın anlamsız ve riskli olduğu algısının paylaşıımasına yol açabileceği gibi yöneticilere güven duyulmasını da engelleyebilir (Çakıcı, 2010: 29-30).

Geçmişte fikirlerini ifade ederken olumsuz tepkilerle karşılaşan çalışanlar zamanla örgütsel sessizliği tercih edebilmektedir. Çalışanlar; çalıştıkları birimin değiştirilmesi ya da işlerinin zorlaştırılmasından, dışlanmaktan, olayların büyümesinden, üst yönetimin sert tavrından çekinmelerinden, işlerine son verilme ihtimalinden dolayı sessiz kalabilmektedir.

\subsubsection{Koruma Amaçlı (Örgüt Yararına/ Prososyal) Sessizlik}

Van Dyne ve diğerleri (2003: 1368) tarafından literatüre eklenen, fedakârlık ve iş birliği temelinde, örgüt ya da diğer çalışanları korumak amacıyla işle ilgili görüş, bilgi ve düşüncelerin saklı tutulması olarak tanımlanabilen koruma amaçlı sessizlik iki şekilde ortaya çıkmaktadır. Koruma amaçlı sessizliğin temelinde yer alan iki unsurdan ilki çalışanların örgütü koruma güdüsü ile sessizliği tercih etmesi, ikincisi ise diğer çalışanları koruma güdüsü ile hareket etmesidir (Brinsfield, 2009: 146). Koruma amaçlı sessizlik başkalarına odaklanan kasıtlı, proaktif ve örgüt tarafından zorunlu tutulmayan, isteğe bağlı bir davranış olup, savunma amaçlı sessizliğe benzer şekilde bilinçli bir karar üzerine kuruludur. Savunma amaçlı sessizliğin aksine, koruma amaçlı sessizlik başkaları için endişelenildiği ve diğer insanların yararı düşünüldüğü için tercih edilen bir davranıştır (Van Dyne vd., 2003: 1368). Çalışanların koruma amaçlı sessizliği tercih etmesindeki amaç, örgüt, çalışma arkadaşları ve çevrelerinin iyiliği ve geleceği gibi konularda sessizliklerini koruyarak, düşüncelerini örgütün devamlılığını sağlaması için dile getirmemesidir (Öztürk ve Cevher, 2016: 74).

Bireysellik değerleri yüksek batı toplumlarına kıyasla, ülkemiz gibi toplulukçu değerleri yüksek toplumlarda koruma amaçlı sessizlik daha yaygın olarak görülmektedir (Durak, 2012: 57).

\subsubsection{1. İlişkileri Bozmamaya Dayalı Sessizlik}

Çalışanlar örgüt içindeki dayanışmayı, birlik ve beraberliği bozmamak adına muhalif görüşlerini açıklamaktan kaçınabilir, arkadaşını korumak adına onun işteki yetersizliği konusunda sessiz kalabilir (Çakıcı, 2010: 34). Çalışanlar "kol kırılır yen içinde kalır" düşüncesi ile hareket ede- 
rek; çalışma arkadaşları ile ilişkilerinin bozulmaması, çalışanlar arasında kötü bir imaja sahip olmamak, yöneticiler ile arasını bozmamak, İş ortamımda huzursuzluk oluşmaması ya da yanlış anlaşılacaklarını düşündükleri için sessiz kalabilmektedirler.

\subsubsection{Prososyal Eğilime Dayalı Sessizlik}

Çalışanlar, örgüt aleyhine kullanılabilecek özel bir bilgiyi örgütü korumak amacıyla dile getirmeyebilir (Çakıcı, 2010: 34). Türk çalışanların kendilerini ait hissettikleri örgütlerin varlığını ve uyumunu devam ettirme kaygıları bulunmaktadır. Türk çalışanlar için örgütten ayrılmamak sadece bireysel bir karar değildir, örgüt içerisinde gelişen ilişkileri bozmamak, örgüt için kendinden fedakârlık etmek çalışanların örgütsel bağlılıklarını etkilemektedir (Wasti, 2000: 205). Çalışanlar, çalışma arkadaşlarını yönetime şikâyet eder duruma düşmemek, onları korumak ve zor durumda bırakmamak, iş yerinde negatif bir enerji oluşturmamak, iş yerinde olması gereken disiplini bozmamak, çalışma arkadaşlarına laf gelmesini önlemek amacıyla sessiz kalmayı tercih edebilmektedir.

\section{Hipotez Geliştirme}

Araştırmada örgüt kültürü ile örgütsel sessizlik arasındaki ilişkilerin belirlenmesi amaçlanmaktadır ve bu doğrultuda önceki bölümlerde sunulmuş olan literatüre bağlı olarak, Şekil.2'de yer alan teorik model oluşturulmuştur.

Şekil 2. Araştırmanın Teorik Modeli

Örgüt Kültürü Boyutları

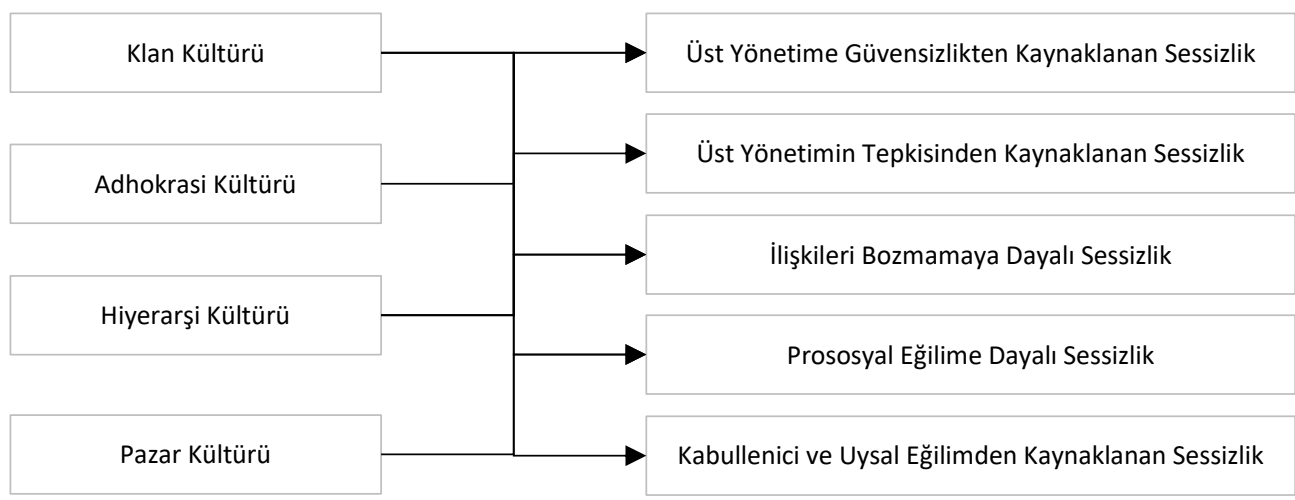

Oluşturulan teorik modele göre, örgüt kültürü ile örgütsel sessizlik arasında ilişki olabileceği varsayılarak şu hipotezler geliştirilmiştir:

H1: Klan kültürü ile üst yönetime güvensizlikten kaynaklanan sessizlik davranışı arasında anlamlı bir ilişki vardır.

H2: Klan kültürü ile üst yönetimin tepkisinden kaynaklanan sessizlik davranışı arasında anlamlı bir ilişki vardır.

H3: Klan kültürü ile ilişkileri bozmamaya dayalı sessizlik davranışı arasında anlamlı bir ilişki vardır.

H4: Klan kültürü ile prososyal eğilime dayalı sessizlik davranışı arasında anlamlı bir ilişki vardir. 
H5: Klan kültürü ile kabullenici ve uysal eğilimden kaynaklanan sessizlik davranışı arasında anlamlı bir ilişki vardır.

H6: Adhokrasi kültürü ile üst yönetime güvensizlikten kaynaklanan sessizlik davranışı arasında anlamlı bir ilişki vardır.

H7: Adhokrasi kültürü ile üst yönetimin tepkisinden kaynaklanan sessizlik davranışı arasında anlamlı bir ilişki vardır.

H8: Adhokrasi kültürü ile ilişkileri bozmamaya dayalı sessizlik davranışı arasında anlamlı bir ilişki vardır.

H9: Adhokrasi kültürü ile prososyal eğilime dayalı sessizlik davranışı arasında anlamlı bir ilişki vardır.

H10: Adhokrasi kültürü ile kabullenici ve uysal eğilimden kaynaklanan sessizlik davranışı arasında anlamlı bir ilişki vardır.

H11: Hiyerarşi kültürü ile üst yönetime güvensizlikten kaynaklanan sessizlik davranışı arasında anlamlı bir ilişki vardır.

H12: Hiyerarşi kültürü ile üst yönetimin tepkisinden kaynaklanan sessizlik davranışı arasında anlamlı bir ilişki vardır.

H13: Hiyerarşi kültürü ile ilişkileri bozmamaya dayalı sessizlik davranışı arasında anlamlı bir ilişki vardır.

H14: Hiyerarşi kültürü ile prososyal eğilime dayalı sessizlik davranışı arasında anlamlı bir ilişki vardır.

H15: Hiyerarşi kültürü ile kabullenici ve uysal eğilimden kaynaklanan Sessizlik davranışı arasında anlamlı bir ilişki vardır.

H16: Pazar kültürü ile üst yönetime güvensizlikten kaynaklanan sessizlik davranışı arasında anlamlı bir ilişki vardır.

H17: Pazar kültürü ile üst yönetimin tepkisinden kaynaklanan sessizlik davranışı arasında anlamlı bir ilişki vardır.

H18: Pazar kültürü ile ilişkileri bozmamaya dayalı sessizlik davranışı arasında anlamlı bir ilişki vardır.

H19: Pazar kültürü ile prososyal eğilime dayalı sessizlik davranışı arasında anlamlı bir ilişki vardır.

H20: Pazar kültürü ile kabullenici ve uysal eğilimden kaynaklanan sessizlik davranışı arasında anlamlı bir ilişki vardır.

\section{Araştırmanın Metodolojisi}

\subsection{Araştırmanın Amacı}

Araştırmanın temel amacı, örgüt kültürü ile örgütsel sessizlik arasındaki ilişkinin açıklanmasıdır ve bu araştırmada örgüt kültürü ile örgütsel sessizlik arasında ilişki olduğu varsayımı sınanmıştır. 


\subsection{Araştırmanın Yöntemi ve Veri Toplama Aracı}

$\mathrm{Bu}$ araştırmada, nicel araştırma yöntem ve tekniklerinden faydalanılmış ve ihtiyaç duyulan verileri toplamak için anket yöntemi kullanılmıştır. Araştırmada kullanılan anket formu, çalışanlarla ilgili bilgileri, çalışanların örgüt kültürü değerlendirmeleri ve çalışanların sessiz kalma nedenleri ile ilgili soruları kapsayan üç bölümden oluşmaktadır.

Araştırmada kullanılan anket formunun birinci bölümünde, demografik bilgileri belirlemeye yönelik sekiz soru bulunmaktadır. Bu sorular ile katılımcıların; yaşı, cinsiyeti, medeni durumu, öğrenim durumu, toplam çalışma süresi, kurumdaki çalışma yılı, unvanı ve hangi kurumda çaIışmakta oldukları ile ilgili verilere ulaşılması amaçlanmıştır.

Anket formunun ikinci bölümü, Cameron ve Quinn'in örgüt kültürü modeli esas alınarak Deshpande ve arkadaşları (1993) tarafından geliştirilen ölçek, klan, adhokrasi, hiyerarşi ve pazar kültürlerini belirlemeye yönelik ve daha önce Erdem (2007a)'in çalışmasında da kullanılan 16 ifadeden oluşmaktadır. Ankette, dört örgüt kültürü (klan, hiyerarşi, adhoktasi ve pazar) tipinin her biri için dörder ifade bulunmaktadır. Çalışanlardan, kurumlarını yakından tanımlayan ifadelere daha fazla, kurumlarıyla az ilgili olan ifadelere daha az olmak üzere 100 puanı dört örgüt kültürü tipini temsil eden ifadelere dağıtmaları istenmiştir.

Anket formunun üçüncü bölümünde, Alparslan ve diğerleri (2015) tarafından sessiz kalma nedenlerini ortaya çıkarmak ve ölçmek amacıyla geliştirilen ölçek kullanılmıştır. Üst yönetime güvensizlikten kaynaklanan sessizlik, üst yönetimin tepkisinden kaynaklanan sessizlik, ilişkileri bozmamaya dayalı sessizlik, prososyal eğilime dayalı sessizlik, kabullenici ve uysal eğilimden kaynaklanan sessizlik olarak örgütsel sessizliği 5 boyutta elen alan ve 5'li Likert tipinde hazırlanan ölçek toplam 33 ifadeden oluşmaktadır.

\subsection{Araştırmanın Ön Kabulleri}

Özel sektöre kıyasla, iş güvenceleri daha fazla olan kamu çalışanlarının sessiz kalıp kalmama davranışlarından hangisini seçecekleri konusunda daha rahat karar alabilecekleri, sessizlik tercihlerini işlerini kaybetme korkusu ile değil de kendi kararları doğrultusunda şekillendirebilecekleri varsayımı ile araştırma kamu kurumlarında yapılmıştır.

\subsection{Araştırma Verilerinin Toplanması}

Bu araştırma, Burdur il merkezindeki kamu kurumlarında görev yapmakta olan çalışanlar üzerinde gerçekleştirilmiş olup, yüz yüze ve elektronik posta yoluyla anketler örneklemi oluşturan kamu personeline uygulanmıştır. Mehmet Akif Ersoy Üniversitesi çalışanlarının bir kısmına ise elektronik posta yolu ile ulaşıımış, katılımcıların anket sorularına ulaşabilmesi için araştırmanın amacını içeren yönerge ve soruların cevaplandırılmasına yardımcı olacak bilgilerin de yer aldığı internet adresi ile veriler toplanmıştır. Değerlendirme öncesi anket verilerinin uygun şekilde cevaplanıp cevaplanmadığı kontrol edilmiş ve soruların eksiksiz şekilde cevaplandırıldığı anketler değerlendirmeye alınmıştır.

\subsection{Kullanılan İstatistiksel Yöntemler}

Örgütsel sessizlik ölçeğinin geçerlilik ve güvenirliliğini belirlemek amacıyla doğrulayıcı faktör analizi yapılmıştır. Araştırma kapsamında elde edilen veriler Statistical Package for the Social Sciences (Sosyal Bilimler İçin İstatistik Paketi) 22.0 programı ile analiz edilmiş ve bulgular yorumlanarak değerlendirilmiştir. Demografik özellikleri belirlemek için frekans ve yüzde dağılımı yöntemleri kullanılmıştır. Araştırmada güvenilirlik analizleri yapılarak Cronbach Alpha $(\alpha)$ değerleri hesaplanmıştır. Örgüt kültürü ve örgütsel sessizlik arasındaki ilişkileri belirlemek amacıyla korelasyon analizi yapılmıştır. 


\subsection{Araştırmanın Evreni ve Örneklemi}

Örgüt kültürü ile örgütsel sessizlik arasındaki ilişkinin açıklanması amacıyla yapılan bu çalışmanın evrenini Burdur îl Merkezindeki kamu kurumlarında görev yapmakta olan yaklaşık 7000 çalışan oluşturmaktadır. Evren sayısı dikkate alındığında, \%5 hata toleransı ve \%95 güvenilirlik düzeyi aralığında, örneklem 365 kişi olarak hesaplanmıştır. 2016 yılında Burdur il Merkezindeki kamu kurumlarında görev yapan çalışan sayıları göz önünde bulundurularak örneklem alanı belirlenmiş ve 2016 yılı Mayıs ayında başlayan anket çalışması 2017 yılı Mart ayında tamamlanmıştır.

Araştırma kapsamında Burdur il Merkezindeki kamu kurumlarında görev yapmakta olan 1000 çalışana ulaşılması hedeflenmiş ve hedef doğrultusunda 1000 anket formu dağıtılmıştır. Araştırmaya gönüllü olarak katılan 876 kamu çalışanına anketler uygulanmış ancak 45 anket formu cevapların güvenilirliğinden şüphe edilerek değerlendirmeye alınmamıştır. Değerlendirmeye alınmayan anketler çıkarıldıktan sonra yeterli sayıda olduğu ve evreni temsil ettiği düşünülen 831 anket formu analize dâhil edilerek, elde edilen veriler için istatistiksel analizler yapılmıştır.

\subsection{Araştırmanın Bulguları}

Örgüt kültürü ile örgütsel sessizlik arasındaki ilişkinin belirlenmesi amacıyla yapılan araştırmada elde edilen verilerin analizi sonucu ulaşılan bulgular çerçevesinde araştırma değerlendirilmiştir.

\subsection{1.Örgütsel Sessizlik Ölçeğine Ait Doğrulayıcı Faktör Analizi Bulguları}

Genellikle ölçek geliştirme ve geçerlilik analizlerinde veya önceden belirlenmiş bir yapının doğrulanması amaçlandığında kullanılan bir analiz yöntemi olan doğrulayıc faktör analizi (DFA), önceden oluşturulan bir model aracılığıyla gözlenen değişkenlerden yola çıkarak gizil değişken (faktör) oluşturmaya yönelik bir işlemdir (Aytaç ve Öngen, 2012: 16). Doğrulayıcı faktör analizi, geleneksel yöntemle yapılan faktör analizlerinden farklı olarak, daha önceden araştırmacı tarafından belirlenen bir faktöryel yapının doğrulanmasını test etmek amacıyla kullanılmaktadır (Erdoğan vd., 2007: 10).

Cameron ve Quinn'in modeli esas alınarak Deshpande ve arkadaşları (1993) tarafından geliştirilen ve daha önce Erdem (2007a)'in çalışmasında da kullanılan bir ölçek olması nedeniyle örgüt kültürü ölçeği için doğrulayıcı faktör analizi yapılmamıştır. Örgütsel sessizlik ölçeği için doğrulayıcı faktör analizinden faydalanılmıştır ve bu ölçeğe ait doğrulayıcı faktör analizi modeli Şekil 3'te yer almaktadır. 
Şekil 3. Örgütsel Sessizlik Ölçeğine Ait Doğrulayıcı Faktör Analizi Modeli

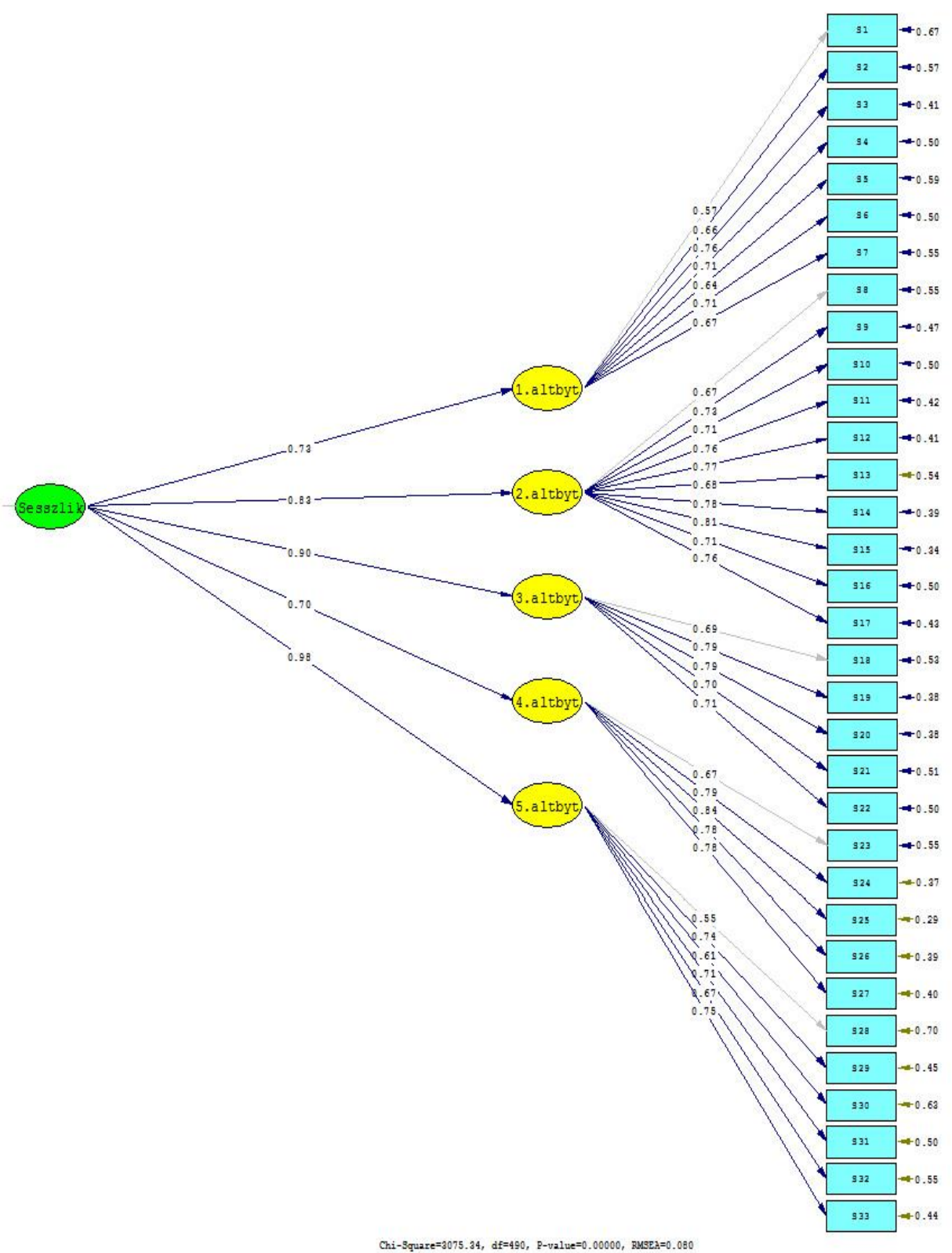

Doğrulayıcı faktör analizi sonuçlarına göre öncellikle $p$ değerinin incelenmesi gerekmektedir. Anlamlılık değeri olan $p$, beklenen kovaryans matrisi ile gözlenen kovaryans matrisi arasındaki farkın ( $x^{2}$ değerinin) manidarlığı hakkında bilgi vermektedir. DFA'da $p$ değerinin anlamlı 
olması beklenir (Çokluk vd., 2012: 257). Bu değer $p=0,000(p<0,05)$ olarak elde edilmiştir. Beklenen kovaryans matrisi ile gözlenen kovaryans matrisi arasındaki fark anlamlıdır. Modele ilişkin uyumluluk indeksleri Tablo 1'de yer almaktadır.

Tablo 1. Doğrulayıcı Faktör Analizine Ilişkin Bulgular

\begin{tabular}{|c|c|c|c|c|}
\hline Index & Mükemmel Uyum Ölçütü & Kabul Edilebilir Uyum Ölçütü & $\begin{array}{l}\text { Araştırma } \\
\text { gusu }\end{array}$ & Bul- \\
\hline$\chi^{2} / s d$ & $0-3$ & $3-5$ & 6,27 & \\
\hline RMSEA & $0,00 \leq \mathrm{RMSEA} \leq 0,05$ & $0,05 \leq \mathrm{RMSEA} \leq 0,10$ & 0,07 & \\
\hline $\mathrm{CFI}$ & $0,95 \leq \mathrm{CFI} \leq 1,00$ & $0,90 \leq \mathrm{CFI} \leq 0,95$ & 0,96 & \\
\hline NNFI & $0,95 \leq \mathrm{NNFI}(\mathrm{TLI}) \leq 1,00$ & $0,90 \leq \mathrm{NNFI}(\mathrm{TLI}) \leq 0,95$ & 0,96 & \\
\hline NFI & $0,95 \leq \mathrm{NFI} \leq 1,00$ & $0,90 \leq \mathrm{NFI} \leq 0,94$ & 0,95 & \\
\hline SRMR & $0,00 \leq S R M R \leq 0,05$ & $0,05 \leq S R M R \leq 0,08$ & 0,07 & \\
\hline GFI & $0,95 \leq \mathrm{GFI} \leq 1,00$ & $0,85 \leq \mathrm{GFI} \leq 0,95$ & 0,78 & \\
\hline AGFI & $0,90 \leq \mathrm{AGFI} \leq 1,00$ & $0,80 \leq \mathrm{AGFI} \leq 0,90$ & 0,75 & \\
\hline
\end{tabular}

Doğrulayıcı faktör analizinde, öncelikle incelenmesi gereken uyumluluk indeksi Ki-kare $\left(X^{2}\right)$ uyum istatistiğidir ve serbestlik derecesine olan oranının 3 'ün altında olması mükemmel uyum, 3 ve 5 arasında olması ise iyi uyum olduğu anlamına gelmektedir. Ki-kare testi tek başına bir modelin kabulü veya reddinde kullanılamaz. Model ne kadar karmaşık olursa ki-kare değeri de o kadar uygun çıkar ancak modelin karmaşıklığı istenmeyen bir durumdur. Örnek büyüklüğünün fazla olduğu durumlarda da büyük ihtimalle ki-kare modelin reddine karar verecektir (Ayyıldız ve Cengiz, 2006: 78). Bu oran örgütsel sessizlik ölçeğine ait doğrulayıcı faktör analizinde 6,27 olarak bulunmuştur

RMSEA; hata karelerinin ortalamasının karekökü olup, modelin anlamlı olabilmesi için RMSEA'nın 0,05 veya daha düşük bir değer alması gerekir. 0,05'den küçük olduğunda mükemmel uyum, 0,05 ile 0,08 arası bir değer alan bir modelin uyumu yeterlidir ve iyi uyum olduğu anlamına gelmektedir. 0,10 ve daha üzeri bir değer aldığında ise modelin uygunluğu zayıftır (Ayyıldız ve Cengiz, 2006: 78). Örgütsel sessizlik ölçeğinde 0,07 olarak bulunan RMSEA değeri iyi uyum göstermektedir.

CFI; model tarafından tahmin edilen kovaryans matrisi ile sıfır hipotezli modelin kovaryans matrisini karşılaştıran bir uyum indeksidir. 0 ile 1 arasında değişen değerler almakta olan CFI değeri; 0,95 ile 1 arasında modelin iyi uyum içinde olduğunu, 0,90 ile 0,95 arasında modelin kabul edilebilir uyum içinde olduğu göstermektedir. CFI indeksi günümüzde yapısal eşitlik modellerinde en yaygın olarak kullanılan uyum indeksidir (Hooper vd., 2008: 55). Araştırmanın 0,96 bulunan CFI değeri mükemmel uyumu göstermektedir.

$\mathrm{NFI}$; normlaştırılmış uyum indeksi olup, CFI'ya alternatif olarak Bentler ve Bonett (1980) tarafından geliştirilmiştir. Bu indeks varsayılan modelin temel ya da sıfır hipoteziyle olan uygunluğunu araştırır (Şehribanoğlu, 2005: 4). Örgütsel sessizlik ölçeği için NFI değeri 0,95 olarak elde edilmiştir ve mükemmel uyum olduğunu göstermektedir. Ayrıca normlaştırılmamış uyum indeksi olan NNFI değeri ise 0,96 olarak bulunmuştur ve bu değer de mükemmel uyum olduğunu ifade etmektedir. 
GFI, varsayılan modelce hesaplanan, gözlenen değişkenler arasındaki genel kovaryans miktarını göstermektedir. 0 ile 1 arasında değişen GFI değerinin 0,90’ı aşması iyi bir model göstergesi olarak anlaşılmaktadır ve bu gözlenen değişkenler arasında yeterince kovaryansın hesaplandığı anlamına gelmektedir. GFI testinin yüksek örnek hacmindeki eksikliği gidermek amacıyla kullanılan bir indekstir. Değeri 0 ile 1 arasında değişir ve negatif değer alırsa bu durum örnek hacminin çok küçük olduğunu veya modelin kötü bir uyum iyiliği gösterdiğini, 1'den büyük değer alışı da tam tanımlanmış bir modelin varlığına işarettir (Ayyıldız ve Cengiz, 2006: 79). GFI değeri 0,78 ve düzenlenmiş uyum indeksi AGFI değeri ise 0,75 olarak bulunmuştur ve zayıf uyum göstermektedir.

Standartlaştırılmış ortalama hataların karekökü olan SRMR değeri 0'a yaklaştıkça modelin uyum iyiliği artar. Model, 0,05'ten düşük bir SRMR değeri almışsa iyi uyum, 0,05 ile 0,08 arasında bir SRMR değeri almışsa kabul edilebilir uyum içerisindedir (Hu ve Bentler, 1999). Araştırmada bulunan 0,07'lik değer iyi uyumu göstermektedir. Sonuçlar genel olarak değerlendirildiğinde modelin doğrulandığı söylemek mümkündür.

\subsubsection{Demografik Bulgular}

Araştırmaya katılan ve Burdur il merkezindeki kamu kurumlarında görev yapmakta olan çalışanların demografik özelliklerine göre dağılımları Tablo 2' de gösterilmiştir.

Tablo 2. Burdur il Merkezindeki Kamu Kurumlarında Görev Yapmakta Olan Çalışanların Demografik Değişkenlere Göre Dağılımı

\begin{tabular}{|c|c|c|}
\hline Değişkenler & Frekans & Yüzde (\%) \\
\hline \multicolumn{3}{|l|}{ Yaş } \\
\hline-30 & 159 & 19,134 \\
\hline $31-40$ & 309 & 37,184 \\
\hline $41-50$ & 259 & 31,167 \\
\hline $51+$ & 104 & 12,515 \\
\hline \multicolumn{3}{|l|}{ Cinsiyet } \\
\hline Kadın & 290 & 34,898 \\
\hline Erkek & 541 & 65,102 \\
\hline \multicolumn{3}{|l|}{ Medeni Durum } \\
\hline Bekâr & 150 & 18,051 \\
\hline Evli & 681 & 81,949 \\
\hline \multicolumn{3}{|l|}{ Öğrenim Durumu } \\
\hline Lise ve altı & 142 & 17,088 \\
\hline Ön lisans & 162 & 19,495 \\
\hline Lisans & 381 & 45,848 \\
\hline Lisansüstü & 146 & 17,569 \\
\hline \multicolumn{3}{|c|}{ Toplam Çalışma Süresi (YıI) } \\
\hline $0-5$ & 146 & 17,569 \\
\hline $6-10$ & 149 & 17,930 \\
\hline $11-15$ & 116 & 13,959 \\
\hline $16-20$ & 142 & 17,088 \\
\hline $21-25$ & 97 & 11,673 \\
\hline $26+$ & 181 & 21,781 \\
\hline \multicolumn{3}{|c|}{ Kurumdaki Hizmet Süresi (Yıl) } \\
\hline $0-5$ & 299 & 35,981 \\
\hline $6-10$ & 168 & 20,217 \\
\hline $11-20$ & 202 & 24,308 \\
\hline $20+$ & 162 & 19,495 \\
\hline \multicolumn{3}{|l|}{ Unvan } \\
\hline V.H.K.I. / Memur & 380 & 45,728 \\
\hline
\end{tabular}




\begin{tabular}{|c|c|c|}
\hline Mühendis/ Mimar/ Şehir Plancısı & 53 & 6,378 \\
\hline Polis Memuru/ Komiser & 26 & 3,129 \\
\hline Öğretim Üyesi / Öğretim Gör./ Araştırma Görevlisi & 98 & 11,793 \\
\hline Sağlık Personeli (Doktor/ Sağlık Memuru/ Ebe/ Hemşire/Radyoloji Teknikeri) & 40 & 4,813 \\
\hline Yardımcı personel (Hizmetli/ Koruma ve Güvenlik Görevlisi/ Bekçi/ Şoför) & 37 & 4,452 \\
\hline İmam Hatip/ Müezzin Kayyım & 30 & 3,610 \\
\hline Uzman Yardımcısı/ Uzman/ Şef/ Araştırmacı & 62 & 7,461 \\
\hline Müdür Yardımcısı/ Müdür/ Yüksek Okul Sekreteri/ Fakülte Sekreteri & 33 & 3,971 \\
\hline Tekniker/Teknisyen & 45 & 5,415 \\
\hline Diğer & 27 & 3,249 \\
\hline \multicolumn{3}{|l|}{ Çalıştığı Kurum } \\
\hline Defterdarlık & 91 & 10,951 \\
\hline Mehmet Akif Ersoy Üniversitesi & 155 & 18,652 \\
\hline Sağlık Bakanlığına Bağlı Kurumlar & 79 & 9,507 \\
\hline Sosyal Güvenlik Kurumu III Müdürlüğü & 90 & 10,830 \\
\hline Milli Eğitim Müdürlüğü & 91 & 10,951 \\
\hline Orman ve Su İşleri Bakanlığına Bağlı Kurumlar & 45 & 5,415 \\
\hline Gıda Tarım ve Hayvancılık İI Müdürlüğü & 35 & 4,212 \\
\hline Müftülük & 34 & 4,091 \\
\hline Çevre ve Şehircilik Bakanlığına Bağlı Kurumlar & 48 & 5,776 \\
\hline İçişleri Bakanlığına Bağlı Kurumlar & 117 & 14,079 \\
\hline Diğer & 46 & 5,535 \\
\hline TOPLAM & 831 & 100 \\
\hline
\end{tabular}

Araştırmaya katılan çalışanların \%37,184'ü 31-40 yaş aralığında, \%65,102'i erkek, \%81,949'u evli, \%45,848'i lisans mezunudur. Katılımcıların \%21,781'inin toplam çalışma süresi 26 yıl ve üzeridir, kurumdaki hizmet süresi ise \%35,981'inin 0-5 yıl aralığında, 18,652'i V.H.K.í. /Memurdur. Katılımcıların \%18,652'i Mehmet Akif Ersoy Üniversitesi çalışanlarıdır.

\subsection{3. Örgüt Kültürü ve Örgütsel Sessizlik Boyutlarının Psikometrik Değerleri}

Araştırmada, örgüt kültürü ve örgütsel sessizlik ölçeklerinde yer alan boyutlara ait psikometrik değerler Tablo 3' de yer almaktadır.

\section{Tablo 3. Boyutların Psikometrik Değerleri}

\begin{tabular}{llllllll}
\hline \multicolumn{1}{c}{ Boyutlar } & $\begin{array}{l}\text { Ifade } \\
\text { Sa- } \\
\text { yısı }\end{array}$ & $\begin{array}{l}\text { Max.- } \\
\text { Min. } \\
\text { Değer- } \\
\text { ler }\end{array}$ & $\begin{array}{l}\text { Cronbach } \\
\text { Alpha }\end{array}$ & $\begin{array}{l}\text { Aritme- } \\
\text { tik Orta- } \\
\text { lama (X) }\end{array}$ & $\begin{array}{l}\text { Standart } \\
\text { Sapma (S) }\end{array}$ & $\begin{array}{l}\text { Çar- } \\
\text { pıklık }\end{array}$ & $\begin{array}{l}\text { Basık- } \\
\text { lık }\end{array}$ \\
\hline Klan Kültürü & 4 & $0-75$ & 0,750 & 21,687 & 11,534 & 0,651 & 1,901 \\
\hline Adhokrasi Kültürü & 4 & $0-55$ & 0,729 & 18,817 & 8,782 & $-0,294$ & 0,354 \\
\hline Hiyerarşi Kültürü & 4 & $0-100$ & 0,848 & 38,439 & 20,399 & 1,233 & 0,920 \\
\hline Pazar Kültürü & 4 & $0-87,5$ & 0,616 & 20,988 & 9,959 & 0,366 & 2,806 \\
\hline $\begin{array}{l}\text { Üst Yönetime Güvensizlikten } \\
\text { Kaynaklanan Sessizlik }\end{array}$ & 7 & $1-5$ & 0,852 & 2,875 & 1,025 & 0,067 & $-0,714$ \\
\hline $\begin{array}{l}\text { Üst Yönetimin Tepkisinden } \\
\text { Kaynaklanan Sessizlik }\end{array}$ & 10 & $1-5$ & 0,921 & 2,136 & 0,924 & 0,760 & 0,031 \\
\hline $\begin{array}{l}\text { İlişkileri Bozmamaya Dayalı } \\
\text { Sessizlik }\end{array}$ & 5 & $1-5$ & 0,855 & 2,599 & 0,963 & 0,263 & $-0,412$ \\
\hline $\begin{array}{l}\text { Prososyal Eğilime Dayalı Ses- } \\
\text { sizlik }\end{array}$ & 5 & $1-5$ & 0,880 & 2,875 & 1,025 & 0,067 & $-0,714$ \\
\hline $\begin{array}{l}\text { Kabullenici ve Uysal Eğilim- } \\
\text { den Kaynaklanan Sessizlik }\end{array}$ & 6 & $1-5$ & 0,828 & 2,567 & 0,930 & 0,214 & $-0,457$ \\
\hline
\end{tabular}

Güvenirlilik analizi, herhangi bir konuda örneklemi oluşturan birimler üzerinden veri toplamak amacı ile geliştirilen ölçme aracını oluşturan ifadelerin kendi aralarında tutarlıık gösterip 
göstermediğini test etmek amacı ile kullanılmaktadır (Ural ve Kılıç, 2011: 258). Güvenilirlik analizleri içerisinde en çok kullanılan Cronbach Alpha değerleri 0 ile 1 arasında değişmektedir ve 0,50 'den daha büyük değerleri kabul edilebilir olarak görülmüştür. Güvenirlilik analizlerinde; 0,50-0,70 arası orta, 0,70-0,80 arası iyi, 0,80-0,90 arası çok iyi ve 0,90 ve üzeri mükemmel düzey olarak ifade edilmektedir (Field, 2002; Akt. Dede ve Yaman, 2008: 25).

Araştırma sonucu boyutların Cronbach Alpha değerlerine bakıldığında; pazar kültürü boyutunun 0,50-0,70 aralığında orta düzeyde, klan ve adhokrasi kültürü boyutlarının 0,70-0,80 aralığında iyi düzeyde, hiyerarşi kültürü, üst yönetime güvensizlikten kaynaklanan sessizlik, ilişkileri bozmamaya dayalı sessizlik, prososyal eğilime dayalı sessizlik, kabullenici ve uysal eğilimden kaynaklanan sessizlik boyutlarının 0,80-0,90 aralığında çok iyi düzeyde ve üst yönetimin tepkisinden kaynaklanan sessizlik boyutunun ise 0,90 ve üzeri mükemmel düzeyde olduğu görülmektedir.

Çarpıklık ve basıklık katsayıları -3 ve +3 aralığında değer alması durumunda normal kabul edilmektedir (Karaatlı, 2010: 6). Çarpıklık ve basıklık katsayılarına bakıldığında, elde edilen değerlerin -3 ile +3 aralığında olması nedeniyle verilerin normal dağıldığı söylenebilir.

Boyutların aritmetik ortalamalarına bakıldığında; örgüt kültürü boyutlarından hiyerarşi kültürü boyutunun en yüksek puanı aldığı $(X=38,439 \pm 20,399)$, adhokrasi kültürü boyutunun ise en düşük puanı aldığı $(X=18,817 \pm 8,782)$ görülmektedir. Katılımcılar, adhokrasi kültürünü belirlemeye yönelik ifadelere en yüksek 55 puan vermişlerdir. Örgütsel sessizlik boyutlarının aritmetik ortalamaları sonucunda, çalışanların en fazla üst yönetime güvensizlikten kaynaklanan sessizliği $(X=2,875 \pm 1,025)$ ve prososyal eğilime dayalı sessizliği $(X=2,875 \pm 1,025)$ tercih ettikleri, üst yönetimin tepkisinden kaynaklanan sessizlik tercihinin ise en düşük puanı $(X=2,136 \pm 0,924)$ aldığı sonuçlarına ulaşılmıştır.

\subsection{4. Örgüt Kültürü ve Örgütsel Sessizlik ile İlgili İfadelerin Aldıkları Puanların Dağılımı}

Araştırmada kullanılan ankette yer alan örgüt kültürü boyutları ile ilgili, klan, adhokrasi, hiyerarşi ve pazar kültürlerinin her biri için 4'er ifade yer almaktadır ve bu ifadelerin aldıkları puanlar ve standart sapmalar Tablo 4'de gösterilmiştir.

Tablo 4. Örgüt Kültürü ile Ilgili ifadelerin Aldıkları Puanların Dağılımı

\begin{tabular}{|c|c|c|c|c|}
\hline Boyut & No & İfadeler & $\begin{array}{l}\text { Aritme- } \\
\text { tik Orta- } \\
\text { lama }(X)\end{array}$ & $\begin{array}{l}\text { Stan- } \\
\text { dart } \\
\text { Sapma } \\
\text { (S) }\end{array}$ \\
\hline \multirow{4}{*}{$\begin{array}{l}\text { Klan } \\
\text { Kültürüu }\end{array}$} & $\mathrm{A} 1$ & $\begin{array}{l}\text { Kurumumuz çok özel bir yerdir. Geniş bir aile gibidir. İnsanlar birçok şeyi } \\
\text { birbirleriyle paylaşırlar. }\end{array}$ & 23,022 & 15,470 \\
\hline & $\mathrm{A} 2$ & $\begin{array}{l}\text { Kurumumuzu bir arada tutan şey sadakat ve geleneklerdir. Bu kuruma } \\
\text { bağlılık yüksektir. }\end{array}$ & 19,868 & 13,744 \\
\hline & A3 & $\begin{array}{l}\text { Kurumumuzun yöneticisi genellikle bir rehber, bilge ya da ana veya baba } \\
\text { gibi düşünülür. }\end{array}$ & 21,735 & 16,231 \\
\hline & A4 & $\begin{array}{l}\text { Kurumumuz insan kaynaklarına önem verir. Kurumda yüksek düzeyde } \\
\text { bağlılık ve moral önemlidir. }\end{array}$ & 22,123 & 15,809 \\
\hline \multirow{4}{*}{$\begin{array}{l}\text { Adhok- } \\
\text { rasi Kül- } \\
\text { türü }\end{array}$} & B1 & $\begin{array}{l}\text { Kurumumuz çok dinamik ve girişimci bir yerdir. İnsanlar tehlikeleri göze } \\
\text { alma arzusundadırlar ve risk alırlar. }\end{array}$ & 17,466 & 11,420 \\
\hline & B2 & $\begin{array}{l}\text { Kurumumuzu bir arada tutan şey yeniliğe ve gelişmeye ilgili olmadır. Öncü } \\
\text { olmaya önem verilir. }\end{array}$ & 19,097 & 12,412 \\
\hline & B3 & $\begin{array}{l}\text { Kurumumuzun yöneticisi genellikle bir girişimci, yenilikçi veya risk alıcı } \\
\text { olarak düşünülür. }\end{array}$ & 18,290 & 11,792 \\
\hline & B4 & $\begin{array}{l}\text { Kurumumuz gelişmeye ve yeni kaynaklara erişmeye önem verir. Yeni de- } \\
\text { ğişimlere karşı hazırlık önemlidir. }\end{array}$ & 20,416 & 11,646 \\
\hline
\end{tabular}




\begin{tabular}{lclcc}
\hline & C1 & $\begin{array}{l}\text { Kurumumuz çok resmi ve yapılandırılmış bir yerdir. İnsanların ne yapacak- } \\
\text { larına genellikle yerleşmiş prosedürler (yazılı kuralları direktifler, talimat- } \\
\text { lar vb.) yön verir. }\end{array}$ & 36,549 & 23,660 \\
\cline { 2 - 5 } $\begin{array}{l}\text { Hiye- } \\
\text { rarşi } \\
\text { Kültürü }\end{array}$ & C2 & $\begin{array}{l}\text { Kurumumuzu bir arada tutan şey resmi kurallar ve tarzlardır. Kurumun } \\
\text { düzenli şleyiş̧ini korumak burada önemli görülür. }\end{array}$ & 37,852 & 23,005 \\
\cline { 2 - 5 } & C3 & $\begin{array}{l}\text { Kurumumuzun yöneticisi genellikle bir koordinatör, bir düzenleyici veya } \\
\text { bir idareci olarak düşünülür. }\end{array}$ & $\mathbf{4 2 , 3 4 6}$ & 26,392 \\
\cline { 2 - 5 } & C4 & $\begin{array}{l}\text { Kurumumuz istikrar ve durağanlığa önem verir. Etkili, düzgün, işlemler } \\
\text { önemlidir. }\end{array}$ & 37,010 & 25,216 \\
\hline & D1 & $\begin{array}{l}\text { Kurumumuz çok üretim yönelimlidir. En çok ilgi çalışanlardan ziyade işle- } \\
\text { rin yapılması üzerinedir. }\end{array}$ & 22,960 & 15,441 \\
\cline { 2 - 5 } Pazar & D2 & $\begin{array}{l}\text { Kurumumuzu bir arada tutan şey görevler ve amaçların gerçekleştirilmesi } \\
\text { üzerine yapılan vurgudur. Üretim merkezli olmak genellikle kabul görür. }\end{array}$ & 23,181 & 14,144 \\
\cline { 2 - 5 } & D3 & $\begin{array}{l}\text { Kurumumuzun yöneticisi genellikle bir üretimci, bir teknisyen veya çetin } \\
\text { bir şoför olarak düşünülür. }\end{array}$ & 17,495 & 14,641 \\
\cline { 2 - 5 } & D4 & $\begin{array}{l}\text { Kurumumuz yarı̧macı faaliyetlere ve başarıya önem verir. Ölçülebilir } \\
\text { amaçlara ulaşmak önemlidir. }\end{array}$ & 20,316 & 14,192 \\
\hline
\end{tabular}

Örgüt kültürü ile ilgili ifadelerin aldıkları puanların dağılımına bakıldığında; hiyerarşi kültür boyutuna ait C1 $(X=36,549 \pm 23,660), C 2 \quad(X=37,852 \pm 23,005), C 3 \quad(X=42,346 \pm 26,392), C 4$ $(X=37,010 \pm 25,216)$ ifadelerin diğer boyutlara ait ifadelerden daha yüksek puan aldığı sonucuna ulaşılmıştır. Özellikle hiyerarşi kültürüne ait "(C3): Kurumumuzun yöneticisi genellikle bir koordinatör, bir düzenleyici veya bir idareci olarak düşünülür." ifadesinin tüm ifadeler arasında en yüksek puanı aldığı görülmektedir. Adhokrasi kültürüne ait "(B1): Kurumumuz çok dinamik ve girişimci bir yerdir. Insanlar tehlikeleri göze alma arzusundadırlar ve risk alırlar." ifadesi ise en düşük puanı $(X=17,466 \pm 11,420)$ almıştır.

Anket formunda örgütsel sessizlik ile ilgili beş boyut ve 33 ifade bulunmaktadır. Bu ifadelerin aldıkları puanların dağılımı Tablo 5'de gösterilmiştir.

Tablo 5. Örgütsel Sessizlik ile Ilgili ifadelerin Aldıkları Puanların Dağılımı

\begin{tabular}{|c|c|c|c|c|}
\hline Boyut & No & İfadeler & $\begin{array}{l}\text { Arit- } \\
\text { metik } \\
\text { Orta- } \\
\text { lama } \\
(X)\end{array}$ & $\begin{array}{l}\text { Stan- } \\
\text { dart } \\
\text { Sapma } \\
\text { (S) }\end{array}$ \\
\hline \multirow{7}{*}{$\begin{array}{l}\text { Üst Yönetime } \\
\text { Güvensizlikten } \\
\text { Kaynaklanan } \\
\text { Sessizlik }\end{array}$} & 1 & Dikkate alınmadığım için sessiz kalırım. & 2,600 & 1,156 \\
\hline & 2 & $\begin{array}{l}\text { Sorun çıkaran, problemli veya şikayetçi biri olarak algılanmak is- } \\
\text { temediğim için sessiz kalırım. }\end{array}$ & 2,599 & 1,195 \\
\hline & 3 & Üst yönetimin arkamda durmayacağını bildiğim için sessiz kalırım. & 2,832 & 1,353 \\
\hline & 4 & Üst yönetimin hakkaniyetine güvenmediğim için sessiz kalırım. & 2,796 & 1,339 \\
\hline & 5 & $\begin{array}{l}\text { Konuşmanın bir yarar sağlamayacağını düşündüğüm için sessiz } \\
\text { kalıım. }\end{array}$ & 2,953 & 1,289 \\
\hline & 6 & Üst yönetimin gözüne batmamak için sessiz kalırım. & 2,460 & 1,230 \\
\hline & 7 & $\begin{array}{l}\text { Üst yönetimin sessiz çalışanı sevmesi, sesini yükselten çalışanı } \\
\text { sevmemesi yüzünden sessiz kalııım. }\end{array}$ & 2,259 & 1,282 \\
\hline \multirow{7}{*}{$\begin{array}{l}\text { Üst Yönetimin } \\
\text { Tepkisinden } \\
\text { Kaynaklanan } \\
\text { Sessizlik }\end{array}$} & 8 & Başka bir birime gönderilme ihtimalinden dolayı sessiz kalırım. & 1,967 & 1,245 \\
\hline & 9 & $\begin{array}{l}\text { Sesimi çıkardığımda tek başına kalmaktan korktuğum için sessiz } \\
\text { kalırım. }\end{array}$ & 2,216 & 1,282 \\
\hline & 10 & Tartışmaya girmekten korktuğum için sessiz kalııım. & 2,182 & 1,203 \\
\hline & 11 & Dışlanmaktan korktuğum için sessiz kalırım. & 1,947 & 1,179 \\
\hline & 12 & İdarecilerin işimi zorlaştırmasından korktuğum için sessiz kalırım. & 2,227 & 1,244 \\
\hline & 13 & İşime son verilme ihtimalinden korktuğum için sessiz kalıım. & 1,855 & 1,179 \\
\hline & 14 & $\begin{array}{l}\text { Görev dağılımında zor duruma düşürülmekten korktuğum için } \\
\text { sessiz kalırım. }\end{array}$ & 2,075 & 1,181 \\
\hline
\end{tabular}


Ağustos 2020, C. 15, S. 2

\begin{tabular}{|c|c|c|c|c|}
\hline & 15 & Üst yönetimin sert tavrından çekindiğim içi sessiz kalırım. & 2,151 & 1,171 \\
\hline & 16 & Olayların büyümesinden korktuğum için sessiz kalııım. & 2,504 & 1,208 \\
\hline & 17 & Misillemeye maruz kalmaktan korktuğum için sessiz kalırım. & 2,237 & 1,202 \\
\hline \multirow{5}{*}{$\begin{array}{l}\text { Ilişkileri Boz- } \\
\text { mamaya Dayalı } \\
\text { Sessizlik }\end{array}$} & 18 & $\begin{array}{l}\text { Çalışma arkadaşlarım ile ilişkilerimin bozulmaması için sessiz kalı- } \\
\text { rım }\end{array}$ & 2,788 & 1,213 \\
\hline & 19 & $\begin{array}{l}\text { Çalışanlar arasında kötü bir imaja sahip olmamak için sessiz kalı- } \\
\text { rım. }\end{array}$ & 2,445 & 1,229 \\
\hline & 20 & Yöneticim ile aramı bozmamak için sessiz kalırım. & 2,353 & 1,222 \\
\hline & 21 & İş ortamımda huzursuzluk oluşmasın diye sessiz kalırım. & 2,917 & 1,192 \\
\hline & 22 & Yanlış anlaşılacağımı düşündüğüm için sessiz kalırım. & 2,493 & 1,195 \\
\hline \multirow{5}{*}{$\begin{array}{l}\text { Prososyal Eği- } \\
\text { lime Dayalı } \\
\text { Sessizlik }\end{array}$} & 23 & $\begin{array}{l}\text { Çalışma arkadaşlarımı yönetime şikâyet eder duruma düşmemek } \\
\text { için sessiz kalırım. }\end{array}$ & 2,628 & 1,306 \\
\hline & 24 & $\begin{array}{l}\text { Çalışma arkadaşlarımı korumak ve onları zor durumda bırakma- } \\
\text { mak için sessiz kalırım. }\end{array}$ & 3,061 & 1,236 \\
\hline & 25 & $\begin{array}{l}\text { Çalışma arkadaşlarım arasında iş yerinde negatif bir enerji oluş- } \\
\text { turmamak için sessiz kalırım. }\end{array}$ & 2,883 & 1,222 \\
\hline & 26 & Olması gereken disiplini bozmak istemediğim için sessiz kalırım. & 2,861 & 1,247 \\
\hline & 27 & Çalışma arkadaşlarıma laf gelmesin diye sessiz kalırım. & 2,944 & 1,225 \\
\hline \multirow{6}{*}{$\begin{array}{l}\text { Kabullenici ve } \\
\text { Uysal Eğilim- } \\
\text { den Kaynakla- } \\
\text { nan Sessizlik }\end{array}$} & 28 & Üst yönetime duyduğum saygıdan dolayı sessiz kalırım. & 2,809 & 1,257 \\
\hline & 29 & Üst yönetim ile aramı bozmamak için sessiz kalırım. & 2,420 & 1,216 \\
\hline & 30 & Uysal ve sessiz bir yapım olduğu için sessiz kalırım. & 2,554 & 1,290 \\
\hline & 31 & $\begin{array}{l}\text { Azınlıkta olduğumu düşündüğümden sessiz kalmayı tercih ede- } \\
\text { rim. }\end{array}$ & 2,316 & 1,199 \\
\hline & 32 & Yasal haklarımızın yetersiz olmasından dolayı sessiz kalırım. & 2,600 & 1,322 \\
\hline & 33 & $\begin{array}{l}\text { Haklıyken haksız duruma düşmekten korktuğum için sessiz kalı- } \\
\text { rım. }\end{array}$ & 2,701 & 1,319 \\
\hline
\end{tabular}

Örgütsel sessizlik ölçeğinde yer alan "Çalışma arkadaşlarımı korumak ve onları zor durumda bırakmamak için sessiz kalırım." (X=3,061 $\pm 1,236)$ ifadesinin yüksek puan aldığı ve çalışanların en çok çalışma arkadaşlarını korumak için prososyal eğilime dayalı sessizliği tercih ettikleri görülmektedir.

Üst yönetimin tepkisinden kaynaklanan sessizlik boyutunda yer alan "İşime son verilme ihtimalinden korktuğum için sessiz kalırım." $(\mathrm{X}=1,855 \pm 1,179)$ ifadesi kamu çalışanlarının iş güvencesi olması nedeniyle en düşük puanı alan ifade olmuştur.

\subsection{5. Örgüt Kültürü ile Örgütsel Sessizlik Arasındaki i̇lişkilere Ait Bulgular}

Örgüt kültürü ile örgütsel sessizlik arasındaki ilişkileri belirlemek amacıyla, bağımsız değişken değiştiğinde bağımlı değişkenin ne yönde değişeceğini görmemizi (Sungur, 2010: 115) sağlayan korelasyon analizi yapılmıştır. Korelasyon analizine ait bulgular Tablo 6' da yer almaktadır. 
Tablo 6. Örgüt Kültürü ile Örgütsel Sessizlik Arasındaki ilişskilere Ait Korelasyon Analizi Bulguları

\begin{tabular}{|c|c|c|c|c|c|c|c|c|c|}
\hline Boyutlar & $\begin{array}{l}\text { Klan Kül- } \\
\text { türü }\end{array}$ & $\begin{array}{l}\text { Adhokrasi } \\
\text { Kültürü }\end{array}$ & $\begin{array}{l}\text { Hiyerarşi } \\
\text { Kültürü }\end{array}$ & $\begin{array}{c}\text { Pazar } \\
\text { Kültürü }\end{array}$ & $\begin{array}{l}\text { Üst Yöne- } \\
\text { time Gü- } \\
\text { vensizlik- } \\
\text { ten Kay- } \\
\text { naklanan } \\
\text { Sessizlik }\end{array}$ & $\begin{array}{l}\text { Üst Yöne- } \\
\text { timin } \\
\text { Tepkisin- } \\
\text { den Kay- } \\
\text { naklanan } \\
\text { Sessizlik }\end{array}$ & $\begin{array}{c}\text { İlişkileri } \\
\text { Bozma- } \\
\text { maya } \\
\text { Dayalı } \\
\text { Sessizlik }\end{array}$ & $\begin{array}{l}\text { Prososyal } \\
\text { Eğilime } \\
\text { Dayalı } \\
\text { Sessizlik }\end{array}$ & $\begin{array}{l}\text { Kabulle- } \\
\text { nici ve } \\
\text { Uysal Eği- } \\
\text { limden } \\
\text { Kaynakla- } \\
\text { nan Ses- } \\
\text { sizlik }\end{array}$ \\
\hline \multirow{2}{*}{ Klan kültürü } & 1 & & & & & & & & \\
\hline & 831 & & & & & & & & \\
\hline \multirow{2}{*}{$\begin{array}{l}\text { Adhokrasi Kül- } \\
\text { türü }\end{array}$} & $0,396^{* *}$ & & & & & & & & \\
\hline & 0,000 & 1 & & & & & & & \\
\hline \multirow{2}{*}{$\begin{array}{l}\text { Hiyerarşi Kül- } \\
\text { türü }\end{array}$} &,$- 726^{* *}$ & $-0,744^{* *}$ & & & & & & & \\
\hline & 0,000 & 0,000 & 1 & & & & & & \\
\hline \multirow[b]{2}{*}{ Pazar Kültürü } & $-0,050$ & $0,199^{* *}$ & $-0,539^{* *}$ & & & & & & \\
\hline & 0,150 & 0,000 & 0,000 & 1 & & & & & \\
\hline \multirow{2}{*}{$\begin{array}{l}\text { Üst Yönetime } \\
\text { Güvensizlik- } \\
\text { ten Kaynakla- } \\
\text { nan Sessizlik }\end{array}$} & $-0,126^{* *}$ & $-0,154^{* *}$ & $0,120^{* *}$ & 0,048 & & & & & \\
\hline & 0,000 & 0,000 & 0,001 & 0,165 & 1 & & & & \\
\hline \multirow{2}{*}{$\begin{array}{c}\text { Üst Yöneti- } \\
\text { min Tepkisin- } \\
\text { den Kaynakla- } \\
\text { nan Sessizlik }\end{array}$} & 0,035 & 0,027 & $-0,038$ & 0,021 & $0,636^{* *}$ & & & & \\
\hline & 0,311 & 0,430 & 0,272 & 0,536 & 0,000 & 1 & & & \\
\hline \multirow{2}{*}{$\begin{array}{l}\text { İlişkileri Boz- } \\
\text { mamaya Da- } \\
\text { yalı Sessizlik }\end{array}$} & 0,061 & $-0,015$ & $-0,041$ & 0,038 & $0,522^{* *}$ & $0,631^{* *}$ & & & \\
\hline & 0,078 & 0,669 & 0,236 & 0,279 & 0,000 & 0,000 & 1 & & \\
\hline \multirow{2}{*}{$\begin{array}{l}\text { Prososyal Eği- } \\
\text { lime Dayalı } \\
\text { Sessizlik }\end{array}$} & 0,028 & $-0,041$ & $-0,026$ & $0,069^{*}$ & $0,425^{* *}$ & $0,446^{* *}$ & $0,679^{* *}$ & & \\
\hline & 0,426 & 0,237 & 0,462 & 0,048 & 0,000 & 0,000 & 0,000 & 1 & \\
\hline \multirow{2}{*}{$\begin{array}{l}\text { Kabullenici ve } \\
\text { Uysal Eğilim- } \\
\text { den Kaynakla- } \\
\text { nan Sessizlik }\end{array}$} & 0,067 & 0,025 & $-0,057$ & 0,029 & $0,593^{* *}$ & $0,704^{* *}$ & $0,730^{* *}$ & $0,605^{* *}$ & \multirow[b]{2}{*}{1} \\
\hline & 0,054 & 0,476 & 0,101 & 0,412 & 0,000 & 0,000 & 0,000 & 0,000 & \\
\hline
\end{tabular}

( ${ }^{*} p<0,01$ anlamlıık düzeyi, ${ }^{*} p<0,05$ anlamlılık düzeyinde korelasyon analizi)

Korelasyon analizi sonucunda, klan kültürü ile üst yönetime güvensizlikten kaynaklanan sessizlik arasında negatif yönde, çok düşük düzeyde, anlamlı bir ilişki olduğu görülmüş $(r=-0,126$; $p<0,01)$. Klan kültürü ile diğer örgütsel sessizlik boyutları arasında istatistiksel olarak herhangi bir ilişki olmadığı ortaya konulmuştur.

Adhokrasi kültürü ile üst yönetime güvensizlikten kaynaklanan sessizlik arasında negatif yönde ve çok düşük düzeyde $(r=-0,154)$, istatistiksel olarak anlamlı bir ilişki olduğu görülmüş $(p<0,01)$ olup, adhokrasi kültürü ile diğer örgütsel sessizlik boyutları arasında istatistiksel olarak anlamlı bir ilişki bulunamamıştır.

Hiyerarşi kültürü ile üst yönetime güvensizlikten kaynaklanan sessizlik arasında pozitif yönde ve çok düşük düzeyde, istatistiksel olarak anlamlı bir ilişki olduğu sonucuna ulaşılmıştır 
$(r=0,120 ; p<0,01)$. Hiyerarşi kültürü ile diğer örgütsel sessizlik boyutları arasında istatistiksel olarak herhangi bir ilişki olmadığı ortaya konulmuştur.

Korelasyon analizi sonucunda, pazar kültürü ile prososyal eğilime dayalı sessizlik arasında, pozitif yönde ve çok düşük seviyede $(r=0,069)$, istatistiksel olarak anlamlı bir ilişki olduğu sonucuna ulaşılmıştır $(p<0,05)$. Pazar kültürü ile diğer örgütsel sessizlik boyutları arasında ise istatistiksel olarak anlamlı bir ilişki bulunamamıştır.

\subsubsection{Araştırma Hipotezlerinin Test Edilmesi}

Örgüt kültürü ile örgütsel sessizlik arasında ilişki olabileceği varsayılarak geliştirilen hipotezlerin kabul edilme ya da reddedilme durumları Tablo 7'de gösterilmektedir.

\section{Tablo 7. Hipotezlerin Kabul/Ret Durumları}

\begin{tabular}{|c|c|}
\hline Hipotez & Kabul/ Ret \\
\hline $\begin{array}{l}\text { H1: Klan Kültürü ile Üst Yönetime Güvensizlikten Kaynaklanan Sessizlik davranışı arasında } \\
\text { anlamlı bir ilişki vardır. }\end{array}$ & Kabul \\
\hline $\begin{array}{l}\text { H2: Klan Kültürü ile Üst Yönetimin Tepkisinden Kaynaklanan Sessizlik davranışı arasında an- } \\
\text { lamlı bir ilişki vardır. }\end{array}$ & Ret \\
\hline $\begin{array}{l}\text { H3: Klan Kültürü ile İlişkileri Bozmamaya Dayalı Sessizlik davranışı arasında anlamlı bir ilişki } \\
\text { vardır. }\end{array}$ & Ret \\
\hline $\begin{array}{l}\text { H4: Klan Kültürü ile Prososyal Eğilime Dayalı Sessizlik davranışı arasında anlamlı bir ilişki } \\
\text { vardır. }\end{array}$ & Ret \\
\hline $\begin{array}{l}\text { H5: Klan Kültürü ile Kabullenici ve Uysal Eğilimden Kaynaklanan Sessizlik davranışı arasında } \\
\text { anlamlı bir ilişki vardır. }\end{array}$ & Ret \\
\hline $\begin{array}{l}\text { H6: Adhokrasi Kültürü ile Üst Yönetime Güvensizlikten Kaynaklanan Sessizlik davranışı ara- } \\
\text { sında anlamlı bir ilişki vardır. }\end{array}$ & Kabul \\
\hline $\begin{array}{l}\text { H7: Adhokrasi Kültürü ile Üst Yönetimin Tepkisinden Kaynaklanan Sessizlik davranışı ara- } \\
\text { sında anlamlı bir ilişki vardır. }\end{array}$ & Ret \\
\hline $\begin{array}{l}\text { H8: Adhokrasi Kültürü ile İlişkileri Bozmamaya Dayalı Sessizlik davranışı arasında anlamlı bir } \\
\text { ilişki vardır. }\end{array}$ & Ret \\
\hline $\begin{array}{l}\text { H9: Adhokrasi Kültürü ile Prososyal Eğilime Dayalı Sessizlik davranışı arasında anlamlı bir } \\
\text { ilişki vardır. }\end{array}$ & Ret \\
\hline $\begin{array}{l}\text { H10: Adhokrasi Kültürü ile Kabullenici ve Uysal Eğilimden Kaynaklanan Sessizlik davranışı } \\
\text { arasında anlamlı bir ilişsi vardır. }\end{array}$ & Ret \\
\hline $\begin{array}{l}\text { H11: Hiyerarşi Kültürü ile Üst Yönetime Güvensizlikten Kaynaklanan Sessizlik davranışı ara- } \\
\text { sında anlamlı bir ilişki vardır. }\end{array}$ & Kabul \\
\hline $\begin{array}{l}\text { H12: Hiyerarşi Kültürü ile Üst Yönetimin Tepkisinden Kaynaklanan Sessizlik davranışı ara- } \\
\text { sında anlamlı bir ilişki vardır. }\end{array}$ & Ret \\
\hline $\begin{array}{l}\text { H13: Hiyerarşi Kültürü ile İlişkileri Bozmamaya Dayalı Sessizlik davranışı arasında anlamlı bir } \\
\text { ilişki vardır. }\end{array}$ & Ret \\
\hline $\begin{array}{l}\text { H14: Hiyerarşi Kültürü ile Prososyal Eğilime Dayalı Sessizlik davranışı arasında anlamlı bir } \\
\text { ilişki vardır. }\end{array}$ & Ret \\
\hline $\begin{array}{l}\text { H15: Hiyerarşi Kültürü ile Kabullenici ve Uysal Eğilimden Kaynaklanan Sessizlik davranışı } \\
\text { arasında anlamlı bir ilişki vardır. }\end{array}$ & Ret \\
\hline $\begin{array}{l}\text { H16: Pazar Kültürü ile Üst Yönetime Güvensizlikten Kaynaklanan Sessizlik davranışı arasında } \\
\text { anlamlı bir ilişki vardır. }\end{array}$ & Ret \\
\hline $\begin{array}{l}\text { H17: Pazar Kültürü ile Üst Yönetimin Tepkisinden Kaynaklanan Sessizlik davranışı arasında } \\
\text { anlamlı bir ilişki vardır. }\end{array}$ & Ret \\
\hline $\begin{array}{l}\text { H18: Pazar Kültürü ile İlişkileri Bozmamaya Dayalı Sessizlik davranışı arasında anlamlı bir } \\
\text { ilişki vardır. }\end{array}$ & Ret \\
\hline $\begin{array}{l}\text { H19: Pazar Kültürü ile Prososyal Eğilime Dayalı Sessizlik davranışı arasında anlamlı bir ilişki } \\
\text { vardır. }\end{array}$ & Kabul \\
\hline $\begin{array}{l}\text { H20: Pazar Kültürü ile Kabullenici ve Uysal Eğilimden Kaynaklanan Sessizlik davranışı ara- } \\
\text { sında anlamlı bir ilişki vardır. }\end{array}$ & Ret \\
\hline
\end{tabular}


Korelasyon analizi sonucunda, klan kültürü ile üst yönetime güvensizlikten kaynaklanan sessizlik arasında negatif yönde ve çok zayıf düzeyde $(r=-0,126 ; p<0,01)$ ilişki olduğu sonucuna ulaşılması nedeniyle $\mathrm{H} 1$ hipotezi kabul edilmiştir.

Adhokrasi kültürü ile üst yönetime güvensizlikten kaynaklanan sessizlik arasında negatif yönde ve çok zayıf düzeyde $(r=-0,154 ; p<0,01)$ ilişki olduğu bulunmuş ve $\mathrm{H} 6$ hipotezi kabul edilmiştir.

Hiyerarşi kültürü ile üst yönetime güvensizlikten kaynaklanan sessizlik arasında pozitif yönde ve çok zayıf düzeyde $(r=0,120 ; p<0,01)$ bir ilişki olduğu sonucuna ulaşılmıştır ve H11 hipotezi kabul edilmiştir.

Pazar kültürü ile prososyal eğilime dayalı sessizlik arasında, pozitif yönde ve çok zayıf düzeyde bir ilişki olduğu sonucuna ulaşılmıştır $(r=0,069 ; p<0,05)$ ve $\mathrm{H} 19$ hipotezi kabul edilmiştir.

Diğer örgüt kültürü tipleri ile örgütsel sessizlik nedenleri arasında bir ilişki bulunamamıştır.

\section{Sonuç}

Rekabetçi değerler modelindeki örgüt kültürü tipleri ile örgütsel sessizlik arasındaki ilişkinin belirlenmesi amaçlanan bu araştırmada, öncelikle örgüt kültürü ile ilgili ifadelerin aldıkları puanların dağılımına bakıldığında; hiyerarşi kültür boyutuna ait ifadelerin diğer boyutlara ait ifadelerden daha yüksek puan aldıkları, özellikle hiyerarşi kültürüne ait "Kurumumuzun yöneticisi genellikle bir koordinatör, bir düzenleyici veya bir idareci olarak düşünülür." ifadesinin tüm ifadeler arasında en yüksek puanı aldığı görülmüştür. Kamu kurumlarındaki yöneticilerin; rehber, girişimci, risk alıcı ya da yol gösterici gibi özelliklerinden daha çok idareci özellikleri ile ön planda oldukları ve kamu çalışanlarının, yöneticilerini bir düzenleyici veya bir idareci olarak tanımladıkları görülmüştür. Adhokrasi kültürüne ait "Kurumumuz çok dinamik ve girişimci bir yerdir. Insanlar tehlikeleri göze alma arzusundadırlar ve risk alırlar." ifadesi ise tüm ifadeler içerisinde en düşük puanı almıştır. Ülkemizdeki kamu kurumlarında rutin işlerin sık yapılması, çalışanların iş güvencesi nedeniyle yeni girişimlerde bulunmaktan ve risk almaktan kaçınmaları gibi nedenlerle, katılımcıların bu ifadeye düşük puan verdikleri düşünülmektedir.

Araştırma bulgularına göre katılımcıların, kurumlarındaki örgüt kültürü tipini daha çok hiyerarşi kültürü ile ilişkilendirdikleri görülmektedir. Hiyerarşi kültürünü sırasıyla klan, pazar ve adhokrasi kültürleri takip etmektedir. Ülkemizde kamu kurumlarının çoğunlukla hiyerarşik örgütlere ait özellikler sergilemesi ve araştırmanın kamu kurumlarında yapılmış olması nedeniyle, araştırma sonuçlarının beklentilere uygun olarak şekillenerek örgüt kültürü boyutlarından hiyerarşi kültürü boyutunun en yüksek puanı aldığı ve adhokrasi kültürü boyutunun ise en düşük puanı aldığı görülmüştür. Çalışanların kurumlarını sadece tek bir örgüt tipi ile ilişkilendirmedikleri görülmüş ve farklı kurumlarda çalışanların örgüt kültürü algılarında farklılıklar olduğu sonucuna ulaşılmıştır.

Örgütsel sessizlik ölçeğinde yer alan "Çalışma arkadaşlarımı korumak ve onları zor durumda bırakmamak için sessiz kalırım" ve "Konuşmanın bir yarar sağlamayacağını düşündüğüm için sessiz kalırım." ifadelerinin yüksek puan aldığı ve çalışanların en çok çalışma arkadaşlarını korumak için prososyal eğilime dayalı sessizliği ve ikinci olarak konuşmalarının bir yarar sağlamayacağını düşünmeleri nedeniyle üst yönetime güvensizlikten kaynaklanan sessizliği tercih ettikleri görülmüştür. Üst yönetimin tepkisinden kaynaklanan sessizlik boyutunda yer alan "işsime son verilme ihtimalinden korktuğum için sessiz kalırım." ifadesi kamu çalışanlarının iş güvencesi olması nedeniyle en düşük puanı alan ifade olmuştur. Kamu kurumlarında iş güvencesinin olması 
nedeniyle üst yönetimin tepkisinden kaynaklanan sessizliğin daha az puan aldığı düşünülmektedir, çünkü herhangi bir sorun karşısında çalışanların karşılaşabilecekleri tepkinin işten ayrılma gibi çok olumsuz sonuçlara neden olma ihtimali oldukça azdır.

Örgütsel sessizlik ile mücadelede örgüt kültürünün önemi oldukça büyüktür, bu nedenle örgütlerde güvene dayalı ve örgütsel sessizliğe neden olmayacak, değişime ve gelişime açık bir örgüt kültürünün oluşturulması gerekmektedir. Örgütsel sessizliğin en az tercih edildiği örgüt kültürü tipinin ve hangi örgüt kültürü tipinde hangi sessizlik türünün görülebileceğinin bilinmesinin, örgütsel sessizliğin önlenmesi ya da olumsuz etkileri ile mücadelede edilmesinde önemli katkılar sağlayacağı düşünülmektedir. Acaray vd. (2015) ile Çavuşoğlu ve Köse (2016) tarafından yapılan araştırmalarda, Cameron ve Quinn (2011)'in rekabetçi değerler modelindeki dört kültür tipinin örgütsel sessizlik üzerindeki etkileri incelenmiştir ve farklı örgüt yapılarında farklı örgütsel sessizlik türleri olduğu sonuçlarına ulaşılmıştır. Bu araştırmada ise, örgütsel sessizlik boyutlarının aritmetik ortalamalarına bakıldığında, çalışanların en fazla üst yönetime güvensizlikten kaynaklanan sessizlik ve prososyal eğilime dayalı sessizlik içerisinde oldukları ortaya çıkmıştır. Çalışanlar, yöneticilerine güvenmedikleri için ya da çalışma arkadaşlarını ve örgütlerini korumak için sessiz kalmayı tercih etmektedirler.

Örgüt kültürü ile örgütsel sessizlik arasındaki ilişkileri belirlemek amacıyla yapılan korelasyon analizi sonucunda klan kültürü ile üst yönetime güvensizlikten kaynaklanan sessizlik arasında negatif yönde ve çok düşük düzeyde bir ilişki bulunmuştur. Aile tipi örgütlere benzeyen, örgüt üyelerinin akraba, yöneticilerin aile büyüğü olarak düşünüldüğü klan kültüründe, karşılıklı ilişkileri korumak önemlidir ve yöneticiler aile büyüğü gibi görülmektedir. Bu nedenle klan kültürüne sahip örgütlerde üst yönetime güvensizlikten kaynaklanan sessizlik davranışı azalacaktır.

Korelasyon analizine göre adhokrasi kültürü ile üst yönetime güvensizlikten kaynaklanan sessizlik arasında da negatif yönde ve çok düşük düzeyde bir ilişki bulunmuştur. Hızla değişmekte olan koşullara uyum sağlayabilmek için ortaya çıkan, temelinde yaratıcılık, girişimcilik, uyumluluk ve dinamizmin yer aldığı, risk almanın ön planda tutulduğu, merkezileşme eğiliminden uzak adhokratik kültürlerde, üst yönetime güven oldukça önemlidir. Çünkü risk almanın desteklendiği bu örgüt kültüründe, alınacak riskler ve kararlar karşısında yönetimin desteğini hissetmek önemlidir. Bu nedenle adhokrasi kültürü değerleri arttıkça üst yönetime güvensizlikten kaynaklanan sessizlik davranışı arasında negatif yönde ilişki ortaya çıkmaktadır.

Korelasyon analizine göre hiyerarşi kültürü ile üst yönetime güvensizlikten kaynaklanan sessizlik arasında pozitif yönde ve çok düşük düzeyde bir ilişki olduğu sonucuna ulaşılmıştır. Biçimsel kuralların, bürokrasinin, yukarıdan aşağıya tek yönlü iletişimin olduğu, itaat, istikrar ve durağanlığa önem verilen hiyerarşi kültürlerinde sessizlik davranışına daha fazla rastlanmaktadır. Merkezi karar verme, yukarı yönlü geribildirim mekanizmalarının olmaması, çalışanların savunma tepkileri gibi örgütsel sessizliğin oluşması için elverişli yapısal ve yönetsel faktörler olması, sessizliği teşvik eden örgüt kültürlerinin oluşmasına neden olmaktadır. Hiyerarşik seviyelerin çok olduğu bu örgütlerde, üst yönetime güvensizlikten kaynaklanan nedenlerle sessizlik davranışı tercih edilmektedir. Örgütsel sessizliğe katkıda bulunan yönetsel inançlar ve hiyerarşik seviyelerin çok olduğu örgütlerde sessizlik daha yaygın olacaktır ve güçlü bir sessizlik ikliminin gelişme olasılığını artıracaktır.

Korelasyon analizinde, Pazar kültürü ile prososyal eğilime dayalı sessizlik arasında pozitif yönde ve çok düşük düzeyde bir ilişki bulunmuştur. Örgütün rekabetçi konumunu ya da pazar payını arttırmak gibi değerlerin ön planda olduğu pazar kültüründe, diğer çalışanları ya da örgütü koruma güdüsü ile prososyal eğilime dayalı sessizlik davranışı tercih edilmiştir. İtibar ve 
başarı ortak endişeleri olan örgüt üyeleri, örgüte fayda sağmak amacıyla sessiz kalmayı tercih edebilmektedir. Örgüt kültürü ile örgütsel sessizlik arasındaki ilişkileri belirlemek amacıyla yapılan korelasyon analizi sonucunda diğer örgüt kültürü tipleri ile örgütsel sessizlik nedenleri arasında bir ilişki bulunamamıştır.

Çalışanların görüş, fikir ve geri bildirimlerini ifade etmelerine engel olan örgütler, çalışanların istenmeyen tepkiler göstermesine ve istenmeyen sonuçlar ortaya çıkmasına neden olmaktadır. Hızla değişen örgütlerde, üst yönetimin ihtiyaç duydukları bilgilere doğru ve hızlı bir biçimde ulaşmaları oldukça önemlidir. Ayrıca etkinliğin ve verimliliğin arttırılabilmesi, çalışanların özgüvenlerinin artması, kendilerini önemli ve örgüte ait hissetmelerini sağlamak açısından örgütsel sessizlik ile mücadele etmek önemli bir hale gelmektedir. Yöneticilerin kritik önem taşıyan konularda çalışanların da fikir ve görüşlerine başvurmaları, çalışanların fikir ve görüşlerini açıkça ifade etmeleri hususunda onları cesaretlendirmeleri gerekmektedir. Böylelikle, örgütsel sessizliğin, örgütün değişimi ve gelişimine engel olmasının önüne geçilebilecektir.

Genellikle çok sayıda standart prosedürün, hiyerarşik seviyenin ve kuralların olduğu kamu kurumlarında hiyerarşi kültürü hâkimdir (Riggio, 2014/2003: 436; Cameron ve Quinn, 2011: 4142). Hiyerarşik örgüt yapılarının özelliklerini taşıyan kamu kurumlarında, kararların üst yönetim tarafından alınması, çalışanların fikir ve görüşlerine önem verilmemesi, çalışanlar arasında ayrım yapılması, fazla çalışmanın desteklenmemesi, zaman zaman yaptırımlarla karşılaşması gibi nedenler sonucu bu örgütlerde çalışanlar arasında sessizlik davranışı görülebilmektedir. Genellikle yöneticilerden korkulması ve onlara güvenilmemesi de çalışanların sessizlik tercihini şekillendirmektedir. Hiyerarşi kültür özellikleri gösteren kamu kurumlarında, yöneticilerin çalışanlar ile arasındaki bağı güçlendirmeleri ve çalışanların yöneticilere güveninin sağlanmasının tüm toplumun yararına olacaktır.

Çalışanların ait oldukları örgütlere göre örgütsel sessizlik tercihleri arasında farklılıklar olabilmektedir. Araştırmanın kamu kurumlarında yapılmış olması ve çalışanların iş güvencesi olması nedeniyle, oldukça az sayıda örgüt kültürü ile örgütsel sessizlik boyutu arasında ilişki bulunduğu düşünülmektedir.

Gelecekte yapılacak araştırmalarda, araştırma verilerinin büyük örneklemlerde ve farklı sektörlerde sınanmasında yarar vardır. Örgüt kültürü ile örgütsel sessizlik arasındaki ilişkilerde sektörel farklılıkları ortaya çıkarmak amacıyla, farklı sektörlerdeki örgüt çalışanlarına araştırmanın yinelenmesi durumunda ortaya çıkabilecek bulgular kıyaslama imkânı sağlayarak faydalı olabilecektir. 


\section{Eskişehir Osmangazi Üniversitesi IïB Dergisi}

\section{Kaynaklar}

Acaray, A., Gündüz Çekmecelioğlu, H., ve Akturan, A., (2015), "Örgüt Kültürü ile Örgütsel Sessizlik Arasındaki illişkilerin İncelenmesi", The Journal of Academic Social Science Studies, 32(3): 139-157.

Acaray A., ve Şevik N., (2016). “Kültürel Boyutların Örgütsel Sessizliğe Etkisi Üzerine Bir Araştırma”, Hacettepe Üniversitesi İktisadi ve İdari Bilimler Fakültesi Dergisi, Cilt 34, Sayı 4, 2016, s. 1-18.

Aktaş, H. ve Şimşek E., (2014), “Örgütsel Sessizlik ile Algılanan Bireysel Performans, Örgüt Kültürü ve Demografik Değişkenler Arasındaki Etkileşim”, Akdeniz i.i.B.F. Dergisi (28) 2014, 24 - 52.

Alparslan, A. M., Can, A. ve Erdem, R., (2015), "Reasons for Employee Silence Behavior: Developing and Validating a Scale for Nurses", Hacettepe Sağlık Idaresi Dergisi, 18(2): 183-204.

Ataman Unutkan, G., (1995), İşletmelerin Yönetimi ve Örgüt Kültürü, 1. Baskı, İstanbul, Türkmen Kitabevi.

Aytaç, Ö., (2007), “Türk Bürokrasi Kültürü: Yönetsel ve Toplumsal Bir Perspektif”, içinde R. Erdem ve C.Ş. Çukur (Ed.), Kültürel Bağlamda Yönetsel-Örgütsel Davranış, (ss. 135-182), 1. Baskı, Ankara: Türk Psikologlar Derneği Yayınları.

Aytaç, M. ve Öngen, B., (2012), Doğrulayıc faktör analizi ile yeni çevresel paradigma ölçeğinin yapı geçerliliğinin incelenmesi, İstatistikçiler Dergisi (5): 14-22.

Ayyıldız, H. ve Cengiz, E., (2006), Pazarlama Modellerinin Testinde Kullanılabilecek Yapısal Eşitlik Modeli (YEM) Üzerine Kavramsal Bir İnceleme, Süleyman Demirel Üniversitesi İktisadi ve İdari Bilimler Fakültesi, 11(1): 63-84.

Brinsfield, C. T., (2009), Employee Silence: Investigation of Dimensionality, Development of Measures, And Examinatıon of Related Factors Dissertation, Yayımlanmamış Doktora Tezi, Ohio State University, Ohio.

Cameron, K. S. ve Quinn, R. E., (2011), Diagnosing and Changing Organizational Culture: Based On The Competing Values Framework, 3. Baskı, The Jossey-Bass Business \& Management Series.

Can, H., Aşan, Ö. ve Aydın, E. M., (2006), Örgütsel Davranış, İstanbul: Arıkan Basın Yayım Dağıtım.

Çakıcı, A., (2010), Örgütlerde Işgören Sessizliği: Neden Sessiz Kalmayı Tercih Ediyoruz?, 1. Baskı, Ankara: Detay Yayıncılık.

Çavuşoğlu, S. ve Köse, S., (2016), "Örgüt Kültürünün Örgütsel Sessizlik Davranışına Etkisi", DEÜ SBE Dergisi, 18(1): 115146.

Çokluk, Ö., Şekercioğlu, G. ve Büyüköztürk, Ş. (2012), Sosyal Bilimler için Çok Değişkenli İstatistik SPSS ve LISREL Uygulamaları, 2. Baskı, Ankara: Pegem Akademi.

Deal, T. E. ve Kennedy, A. A., (1982), Corporate Culture: The Rites and Rituals of Corporate Life, Addison Wesley, Massachusetts.

Dede, Y. ve Yaman, S., (2008), "Fen Öğrenmeye Yönelik Motivasyon Ölçeği: Geçerlik ve Güvenirlik Çalışması", Necatibey Eğitim Fakültesi Elektronik Fen ve Matematik Eğitimi Dergisi, 2(1): 19-37.

Dinçer, Ö., (1998), Stratejik Yönetim ve İşletme Politikası, 5. Baskı, İstanbul: Beta Yayınları.

Durak, I. (2012), Korku kültürü ve Örgütsel Sessizlik. Bursa: Ekin Yayınevi.

Erdem, R., (2007a), "Örgüt Kültürü Tipleri ile Örgütsel Bağlılık Arasındaki İlişki: Elazığ ì Merkezindeki Hastaneler Üzerinde Bir Çalışma", Eskişehir Osmangazi Üniversitesi IiBF Dergisi 2(2): 63-79.

Erdem, R., (2007b), “Toplumsal Kültürün Örgüt Kültürüne Yansımaları”, içinde R. Erdem ve C. Ş. Çukur (Ed.), Kültürel Bağlamda Yönetsel-Örgütsel Davranış, (ss. 91-133), 1. Baskı, Ankara: Türk Psikologlar Derneği Yayınları.

Erdem, R., Adıgüzel, O. ve Kaya, A., (2010), " Akademik Personelin Kurumlarına İlişkin Algıladıkları ve Tercih Ettikleri Örgüt Kültürü Tipleri", Erciyes Üniversitesi İktisadi ve Idari Bilimler Fakültesi Dergisi, (36): 73-88.

Erdoğan, Y., Bayram, S. ve Deniz, L., (2007), Web Tabanlı Öğretim Tutum Ölçeği: Açıklayıcı ve Doğrulayıcı Faktör Analizi Çalışması, Uluslararası İnsan Bilimleri Dergisi, 4(2): 1-14.

Eren, E., (2000), Örgütsel Davranış ve Yönetim Psikolojisi, 6. Baskı, İstanbul: Beta Yayınları.

Hofstede, G. (1980), Culture's consequences: International Differences in Work-related Values, Sage Publications, Inc.

Hooijberg, R. ve Petrock, F., (1993), On Cultural Change: Using the Competing Values Framework to Help Leaders Execute a Transformational Strategy, Human Resource Management, 32(1): 29-50.

Hooper, D., Coughlan, J. ve Mullen, M., (2008), Structural Equation Modelling: Guidelines for Determining Model Fit, Electronic Journal of Business Research Methods, 6(1): 53-60.

Hu, L.T. ve Bentler, P.M., (1999), Cutoff Criteria for Fit Indexes in Covariance Structure Analysis: Conventional Criteria Versus New Alternatives, Structural Equation Modeling, 6 (1): 1-55. 
Karaatlı, M., (2010), “Verilerin Düzenlenmesi ve Gösterimi” içinde Ş. Kalaycı (Ed.), SPSS Uygulamalı Çok Değiş̧enli istatistik Teknikleri, (ss. 3-47), 5. Baskı, Ankara: Asil Yayın Dağıtım.

Milliken, F. J. ve Morrison, E. W., (2003), "Shades of Silence: Emerging Themes and Future Directions for Research on Silence in Organizations", Journal of Management Studies (40)6: 1563 - 1568.

Morrison, E. W. ve Milliken, F. J., (2000), "Organizational Silence: A Barrier To Change And Development in a Pluralistic Academy Of Management", The Academy Of Management Review, (25)4: 706-725.

Ouchi, W. G., (1981), Theory Z, How American Business Can Meet the Japanese Challenge Reading Mass, Addison Wesley.

Özgen, I. ve Sürgevil, O., (2009), “Örgütsel Sessizlik Olgusu ve Turizm İşletmeleri Açısından Değerlendirilmesi”, içinde: Z. Sabuncuoğlu (Ed.), Turizm Işletmelerinde Örgütsel Davranış, (ss. 303-328), Bursa: MKM Yayıncılık.

Özkalp, E. ve Kırel, Ç., (2003), Örgütsel Davranış, 6. Baskı, Bursa: Ekin Basın Yayın Dağıtım.

Öztürk, U. C., ve Cevher, E., (2016), “Sessizlikteki Mobbing: Mobbing ve Örgütsel Sessizlik Arasındaki İlişki “, KMÜ Sosyal ve Ekonomik Araştırmalar Dergisi, 18 (30): 71 - 80.

Peters, T. J., ve Waterman R.H. (1982) In Search of Excellence Lessons from Americas Best Run Companies,, New York: Harper and Row.

Pinder, C. C. ve Harlos, K. P., (2001), “Employee Silence: Quiescence and Acquiescence As Responses to Perceived Injustice", Research in Personnel and Human Resources Management, (20): 331-369.

Riggio, R. E., (2014), Endüstri ve Örgüt Psikolojisine Giriş, (Çev. B. Özkara), 6. Baskı, Ankara: Nobel Yayıncılık. (Orijinal Baskı: 2003)

Schein, E.H., (1983), Organizational Model: A Dynamic Model, https://apps.dtic.mil/dtic/tr/fulltext/u2/a126613.pdf, Erişim Tarihi: 24.02 .2020

Sungur, O., (2010), "Korelasyon Analizi” içinde Ş. Kalaycı (Ed.), SPSS Uygulamalı Çok Değiş̧kenli istatistik Teknikleri, (ss. 115-127), 5. Baskı, Ankara: Asil Yayın Dağıtım.

Şehribanoğlu, S., (2005), Yapısal Eşitlik Modelleri ve Bir Uygulaması, Yayımlanmamış Yüksek Lisans Tezi, Yüzüncü Yıl Üniversitesi Fen Bilimleri Enstitüsü Zootekni Anabilim Dalı, Van.

Taşkıran, E., (2011), Liderlik ve Örgütsel Sessizlik Arasındaki Etkileşim: Örgütsel Adaletin Rolü, 1. Baskı, İstanbul: Beta Basım.

Ural, A. ve Kılıç, İ., (2011), Bilimsel Araştırma Süreci ve SPSS ile Veri Analizi, 3. Baskı, Ankara: Detay Yayıncılık.

Van Dyne. L., Soon, A. ve Botero, I. C., (2003), “Conceptualizing Employee Silence and Employee Voice as Multidimensional Constructs", Journal of Management Studies, (40)6: 1359-1392.

Wasti, S.A., (2000), “Örgütsel Bağlılığı Belirleyen Evrensel ve Külütrel Etmenler: Türk Kültürüne Bir Bakış”, içinde Z. Aycan (Ed.), Türkiye'de Yönetim, Liderlik ve Insan Kaynakları Uygulamaları, (ss. 201-224), 1. Baskı, Ankara: Türk Psikologlar Derneği 


\section{Eskişehir Osmangazi Üniversitesi IïB Dergisi}

\section{Extended Summary}

The Analysis of the Relationship between Organizational Culture and Organizational Silence

Organizational culture is one of the main causes of organizational silence and it is important to consider the silence preferences of employees in terms of cultural values in organizations. The organizational culture model that Cameron and Quinn (1983) call competitive values is divided into four dimensions: clan, adhocracy, hierarchy and market culture. Due to its similarity to a family-type organization, in the clan culture type; organizational commitment is high, teamwork is given importance and managers are seen as a family eld. Adhocracy culture is a type of organizational culture that is dynamic, entrepreneurial, is flexible and reacts fast to conditions that are accelerating day by day. Hierarchy culture is a type of organizational culture that has a formal working environment, governed by procedures. Market culture is a type of result-oriented organizational culture where it is important to take the lead in competition and provide market leadership.

Organizational silence is that employees do not express their thoughts and opinions about the organization and keep them to themselves. Acquiescent silence is what employees are willing to the current situation and behave in a passive manner by avoiding expressing their opinions, information and thoughts for purposes such as not being unemployed or being promoted. Defensive silence is the deliberate hiding of the person's views, information and thoughts with a sense of security, in order to protect himself from external dangers. Prosocial silence is the retention of business opinions, information and thoughts on the basis of sacrifice and cooperation to protect the organization or other employees.

In this study, it is aimed to determine the relationship between organizational silence types in the competitive values model and organizational silence at the organizational level based on the question of which organizational silence type is seen in which organizational culture type. According to the created theoretical model; assuming that there may be a relationship between organizational culture and organizational silence, the following hypotheses have been developed:

$\mathrm{H} 1$ : There is a significant relationship between clan culture and silence behavior arising from lack of confidence in senior management.

$\mathrm{H} 2$ : There is a significant relationship between clan culture and silence behavior based on fear of the senior management.

H3: There is a significant relationship between clan culture and silence behavior based on getting along with coworkers.

$\mathrm{H} 4$ : There is a significant relationship between clan culture and silence behavior based on tendency towards prosocial behavior.

$\mathrm{H} 5$ : There is a significant relationship between clan culture and silence behavior arising from meek personality.

H6: There is a significant relationship between adhocracy culture and silence behavior arising from lack of confidence in senior management.

H7: There is a significant relationship between adhocracy culture and silence behavior based on fear of the senior management.

H8: There is a significant relationship between adhocracy culture and silence behavior based on getting along with co-workers.

H9: There is a significant relationship between adhocracy culture and silence behavior based on tendency towards prosocial behavior.

H10: There is a significant relationship between adhocracy culture and silence behavior arising from meek personality.

H11: There is a significant relationship between hierarchy culture and silence behavior arising from lack of confidence in senior management.

H12: There is a significant relationship between hierarchy culture and silence behavior based on fear of the senior management.

H13: There is a significant relationship between hierarchy culture and silence behavior based on getting along with co-workers.

$\mathrm{H} 14$ : There is a significant relationship between hierarchy culture and silence behavior based on tendency towards prosocial behavior.

$\mathrm{H} 15$ : There is a significant relationship between hierarchy culture and silence behavior arising from meek personality. 
$\mathrm{H} 16$ : There is a significant relationship between market culture and silence behavior arising from lack of confidence in senior management.

H17: There is a significant relationship between market culture and silence behavior based on fear of the senior management.

H18: There is a significant relationship between market culture and silence behavior based on getting along with co-workers.

H19: There is a significant relationship between market culture and silence behavior based on tendency towards prosocial behavior.

$\mathrm{H} 20$ : There is a significant relationship between market culture and silence behavior arising from meek personality.

In this research, a questionnaire form consisting of three parts is used to collect the data needed. In the first part of the questionnaire, there are 8 questions to determine demographic information. The second part of the questionnaire consists of 16 statements to determine clan, adhocracy, hierarchy and market cultures. In the third part of the questionnaire, the scale developed to reveal and measure the reasons for being silent is used. The scale, which takes the organizational silence in 5 dimensions as towards lack of confidence in senior management, fear of the senior management's, getting along with co-workers, tendency towards prosocial behavior, meek personality consists of 33 expressions.

This research is conducted on employees working in public institutions in the city center of Burdur, and surveys are applied to 876 public employees who participated in the study voluntarily, but 45 questionnaire forms are not evaluated by suspecting the reliability of the answers. 831 questionnaire forms, which are represent the universe are included in the analysis. The data obtained within the scope of the research are analyzed with the SPSS 22.0 software. Frequency and percentage distribution methods are used to determine demographic characteristics. Cronbach Alpha $(\alpha)$ values are calculated by conducting reliability analysis in the study. Correlation analysis is conducted to determine the relationship between organizational culture and organizational silence.

As a result of the correlation analysis, $\mathrm{H} 1$ hypothesis is accepted because it is concluded that there is a negative and very weak $(r=-0,126 ; p<0,01)$ relationship between clan culture and silence caused by lack of confidence in senior management. A negative and very weak $(r=-0,154 ; p<0,01)$ relationship is found between adhocracy culture and silence due to lack of confidence in senior management, and the $\mathrm{H} 6$ hypothesis is accepted. It is concluded that there is a positive and very weak $(r=0,120 ; p<0,01)$ relationship between hierarchy culture and silence caused by lack of confidence in senior management, and the $\mathrm{H} 11$ hypothesis is accepted. It is concluded that there is a positive and very weak relationship between market culture and silence based on tendency towards prosocial behavior $(r=0,069 ; p$ $<0,05)$ and $\mathrm{H} 19$ hypothesis is accepted. No relation is found between other types of organizational culture and the causes of organizational silence.

There may be differences between organizational silence preferences according to the organizations they belong to. Since the research is conducted in public institutions and the job guarantee of the employees, it is thought that there is a relationship between a very few organizational culture and organizational silence.

In future researches, it is beneficial to test the research data in large samples and in different sectors. In order to reveal sectoral differences in the relationships between organizational culture and organizational silence, findings that may arise in case of repeated studies in the organization of different sectors may be useful by providing a comparison opportunity. 